NBER WORKING PAPER SERIES

\title{
GOING TO A BETTER SCHOOL: EFFECTS AND BEHAVIORAL RESPONSES
}

Cristian Pop-Eleches

Miguel Urquiola

Working Paper 16886

http://www.nber.org/papers/w16886

\author{
NATIONAL BUREAU OF ECONOMIC RESEARCH \\ 1050 Massachusetts Avenue \\ Cambridge, MA 02138 \\ March 2011
}

For useful feedback we are thankful to Josh Angrist, Ken Chay, Damon Clark, Rajeev Dehejia, Caroline Hoxby, Chang-Tai Hsieh, Lawrence Katz, Ofer Malamud, Richard Murnane, Jonah Rockoff, Amy Schwartz, Douglas Staiger, and Eric Verhoogen; for contributions at early stages of the project, to Andreea Balan. For excellent research assistance we thank Anindya Roy. For financial support, we are grateful to the National Science Foundation (SES 0819776), and to Columbia's Institute for Social and Economic Research and Policy (ISERP) and Program for Economic Research (PER). Urquiola is also grateful to the Russell Sage Foundation. The views expressed herein are those of the authors and do not necessarily reflect the views of the National Bureau of Economic Research.

NBER working papers are circulated for discussion and comment purposes. They have not been peerreviewed or been subject to the review by the NBER Board of Directors that accompanies official NBER publications.

(C) 2011 by Cristian Pop-Eleches and Miguel Urquiola. All rights reserved. Short sections of text, not to exceed two paragraphs, may be quoted without explicit permission provided that full credit, including (c) notice, is given to the source. 
Going to a Better School: Effects and Behavioral Responses

Cristian Pop-Eleches and Miguel Urquiola

NBER Working Paper No. 16886

March 2011

JEL No. I20

\begin{abstract}
$\underline{\text { ABSTRACT }}$
This paper: i) estimates the effect that going to a better school has on students' academic achievement, and ii) explores whether this intervention induces behavioral responses on the part of children, their parents, and the school system. For the first task, we exploit almost 2,000 regression discontinuity quasi-experiments observed in the context of Romania's high school educational system. For the second, we use data from a specialized survey of children, parents, teachers and principals that we implemented in 59 Romanian towns. The first finding is that students do benefit from access to higher achieving schools and tracks within schools. A second set of results suggests that the stratification of schools by quality in general, and the opportunity to attend a better school in particular, result in significant behavioral responses on the part of teachers, parents, and students. Although we do not expect the magnitude or even the direction of these responses to hold everywhere, their existence has a number of implications for evaluation, particularly since some of them change over time, and some would seem to be relevant only once interventions reach a certain scale.
\end{abstract}

Cristian Pop-Eleches

Columbia University

SIPA and Economics Department

1022 International Affairs Building, MC 3308

420 West 118th Street

New York, NY 10027

and NBER

cp2124@ columbia.edu

Miguel Urquiola

Columbia University

SIPA and Economics Department

1022 IAB, MC 3308

420 West 118th Street

New York, NY 10027

and NBER

msu2101@columbia.edu 


\section{INTRODUCTION}

Whether students would benefit from attending higher-achieving schools is an important question in education. For example, part of the rationale underlying No Child Left Behind is that a child in a low-achievement institution would be better off transferring to a higher-scoring school. Clear evidence on this issue is scarce, in large part because students are not randomly allocated to schools. Nevertheless, as discussed below, several papers provide credible estimates of the effect of having access to a better school.

Such estimates do not provide a complete roadmap for policy, however, as they may reflect but not reveal behavioral responses that amplify or reduce the impact of educational quality. For instance, parents might react to their children going to a better school by lowering their own effort. There might also be reactions on the part of students; for example, an individual who makes it into a better school might feel inferior or be stigmatized. ${ }^{1}$ Importantly these responses might change over time, and may thus influence results differently depending on when outcome data are collected. Additionally, some of these responses - which we will refer to as equilibrium effectsmay only emerge once interventions are taken to scale and sustained for a period of time. ${ }^{2}$ To illustrate, stratifying students by ability might lead to reactions in the school system itself, e.g., the emergence of norms that assign more qualified teachers to brighter students. Thus, the very characteristics of an intervention may depend on its reach. The bottom line, as emphasized by Todd and Wolpin (2003), is that knowledge of such behavioral responses is crucial to a full understanding of educational interventions. Yet, there is little evidence on their empirical relevance.

In this context, this paper makes two contributions. First, using administrative data from all of Romania, it provides a rigorous estimate of the impact of going to a better school. Second, it explores the existence of dynamic behavioral responses and equilibrium effects using data from a specialized survey of parents, teachers, and principals that we implemented for three cohorts in a subset of towns.

As stated, our starting point is that identifying the effect of access to a better school is challenging. Nonetheless, several analyses have exploited compelling research designs, with Dale and Krueger (2002), Cullen, Jacob, and Levitt (2006), and Hastings, Kane, and Staiger (2009) providing

\footnotetext{
${ }^{1}$ Partially along these lines, Cullen, Jacob and Levitt (2006) explore how school choice affects students' attitudes and behaviors.

${ }^{2}$ See for example the discussions in Banerjee and Duflo (2008), Acemoglu (2010), and Deaton (2010).
} 
early examples. Several more recent papers rely on regression discontinuity (henceforth RD) designs. Specifically, Park, Shi, Hsieh, and An (2008), Hoekstra (2009), Saavedra (2009), and Jackson (2010a) find that relative to students who just miss gaining admission to high achieving educational institutions, those who make it have better academic and/or labor market outcomes. In contrast, Clark (forthcoming), Duflo, Dupas, and Kremer (forthcoming), and Sekhri and Rubinstein (2010), find scant evidence of impacts from getting into a better school or class (within a school).

We also apply an RD design to Romania's high school system, exploiting the fact that as they transition into secondary education, Romanian children's ability to choose a high school depends solely on a score which is the average of their performance on a nationwide $8^{\text {th }}$ grade test and their grade point average. After obtaining their transition score, students submit a list of high school/track combinations they wish to enroll in (such as Mathematics and Social Studies). These tracks are essentially "schools within a school" in that their students take all their classes together and do not take courses with members of other tracks, although they share inputs like facilities and a principal.

After students have submitted their choices, they are allocated to school/tracks via a nationally centralized process that honors higher scoring students' requests subject to pre-established slot constraints. $^{3}$ This gives rise to cutoff scores that we set equal to the transition score of the child that fills the last slot in a given school/track. We show that there are clear discontinuities in educational quality at these cutoffs. For instance, relative to students who score just below a school cutoff, those who score just above experience, on average, a highly significant increase in the average transition score displayed by their peers.

Pooling data from three cohorts of entering students, this process generates about 2,000 cutoffs and substantial sample sizes. The large number of cutoffs allows us to explore the heterogeneity of school effects-whether being able to attend a more selective school, for example, is more valuable to a student whose initial performance is high or low-something that to our knowledge has not been possible in the previous RD-based research.

We explore the effects of this variation on a "high stakes" outcome: performance on a Baccalaureate exam. Passing this exam is a requirement for application to university, and the grade is used by many institutions as an important admission criterion. We find that students do benefit from access

\footnotetext{
${ }^{3}$ As discussed below, the setting gives students incentives to truthfully reveal their preference rankings.
} 
to higher ranked schools and tracks within schools. Specifically, relative to individuals who just miss scoring above a school cutoff, those who succeed display a statistically significant 0.05 standard deviation advantage in Baccalaureate performance. ${ }^{4}$ If scaled by the associated improvements in peer quality, these effects are of a magnitude consistent with some estimates in the literature. ${ }^{5}$ These effects are often larger and more precisely estimated for cutoffs that occur at higher grade levels.

Having established these results, we turn to exploring behavioral responses. We rely on a specialized survey we administered to teachers, parents, and students in a subset of towns, in a way that allows us to match students to their schools and instructors. The resulting data yield evidence of behavioral responses and equilibrium effects along potentially important dimensions.

For instance, they are consistent with teachers sorting in response to the stratification of students: teachers with higher certification standards are more likely to teach in better-ranked schools. This sorting persists even within schools as one moves from a weaker to a stronger track, and even within tracks as one moves from a weaker to a stronger class. ${ }^{6}$ As a result, although students who score just above a cutoff attend schools that on average have more certified teachers, the marginal (actual) teachers assigned to them are not observably different from those assigned to students who score just below the cutoff. In short, more qualified teachers are matched with higher achieving students. This seems to be an established norm in Romania, perhaps one that reflects a long term outcome of the interplay between teacher and parental preferences, as well as broader political-economy forces.

In terms of parental effort, a first finding is that children who just make it into higher achieving schools receive less homework-related help from their parents. In this sense, Romanian parents may view educational quality and their own effort as substitutes, and this may have real effects once parents understand a tracking policy and expect it to persist. We also find areas where there seems to be no change in parental choices, again leading to differences in average vs. marginal effects. For example, children who make it into better schools/tracks/classes are exposed to peers whose parents are significantly more involved in their education - they participate more at school, and are more likely to devote resources to private tutoring (which is common in Romania) - yet their own parents show no greater sign of such engagement.

\footnotetext{
${ }^{4}$ In a finding that facilitates the interpretation of this result, there is no significant evidence of selection into test taking.

${ }^{5}$ For instance, a one standard deviation increase in peer quality is associated with a $0.1-0.2$ standard deviation increase in Baccalaureate grade performance.

${ }^{6}$ Stratifying students into classes within tracks (when tracks are large enough) is a common but not universal or codified practice in Romanian high schools.
} 
In terms of student responses, we find that children who just make it into better schools perceive themselves as weaker relative to their peers. This is not surprising in a setting in which tracking by ability has been in place a long time and is well understood. Additionally, however, this is associated with greater frequency of negative interactions with peers, providing some evidence that getting into a better school is associated with marginalization.

For the parental and student dimensions, we also find evidence that these responses have a dynamic component. Namely, the RD-estimated feelings of stigmatization and reduction in parental help are strongest earlier in students' high school careers, and diminish over time. This might reflect, for example, students' gradual realization that tracking involves some noise, or parents' realization that their help is necessary even if their child is in a better school. Such dynamics imply that the estimated effects of going to a better school might depend, for example, on whether academic outcomes are measured at the $9^{\text {th }}$ or $12^{\text {th }}$ grade level.

Taken together, these results inform not just the literatures on tracking and school effects, but also the research on experimental analyses of educational policy. Specifically, while we do not expect the exact nature or even the direction of the responses we find to extend to all settings, our results suggest that large scale interventions can result in equilibrium responses by the different actors involved in educational markets. These reactions may not be observed or are explicitly held constant in partial equilibrium interventions. In salient examples, the STAR class size experiment (e.g., Krueger (1999)) and the tracking experiment in Duflo, Dupas, and Kremer (forthcoming) report on contexts in which one dimension of educational quality was manipulated while teacher quality was held constant by randomly assigning instructors to classrooms. In our data, in contrast, relevant measures of teacher quality end up being correlated with educational quality. Similarly, parental effort may not change in a temporary experiment, but might respond once an intervention is sustained.

As stated, such behavioral responses and equilibrium effects may well be setting-specific. For example, Duflo, Dupas, and Kremer (forthcoming) are aware that teacher sorting could happen, and point out that in Kenya this would result in more effective teachers being matched to weaker children. In contrast, Lankford, Loeb, and Wyckoff (2002) suggest that in the U.S., low-achieving students are typically matched with the least-skilled teachers. Similarly, while we find evidence that Romanian parents view school quality and their own effort as substitutes, other parents might 
view them as complements. Again, our point is not that there would be uniformity in responses across all settings, but that such responses may be quantitatively important and hence affect the key characteristics and impacts of an educational intervention. Indeed, the presence or absence of similar behavioral responses might partially account for the mixed findings in the growing RD literature on school effects cited above.

Our work is also related to the literature that studies how families make decisions regarding human capital investments (Becker (1964), Becker (1981), Becker and Tomes (1986)). The empirical literature in this area has usually focused on the impact of parental characteristics on child outcomes (e.g. Behrman et al. (1997), Case and Deaton (1999b), Brown (2006)) without considering parentschool interactions. Das et al. (2010) is a notable exception that studies how parents adjust their educational expenditures in response to anticipated and unanticipated school grants. ${ }^{7}$

Finally, our results are also relevant for theoretical work suggesting that educational interventions should ideally be analyzed with reference to their potential effects on the behavior of agents involved in the educational process, e.g., Das et al. (2010), MacLeod and Urquiola (2009), and Albornoz, Berlinski, and Cabrales (2010).

The remainder of the paper proceeds as follows. Section 2 presents a conceptual framework. Section 3 describes the student allocation mechanism, and sections 4 and 5 our data and methodology, respectively. Section 6 presents results, and Section 7 concludes.

\section{Conceptual Framework}

The range of behavioral responses we focus on can be illustrated with a minor addition to the useful framework set out in Todd and Wolpin (2003). The addition reflects that while Todd and Wolpin focus on responses on the part of households, here we also consider reactions on the part of the school sector itself.

Specifically, consider a three period setting in which period $t=0$ precedes a child entering school, and $t=1$ and $t=2$ denote the first and second years of school, respectively. $F_{t}$ stands for household investments into children's skill acquisition in period $t$, and $\mu$ for a child's innate ability. $W$ denotes family wealth. Finally, let $A_{t}$ indicate a child's achievement at the beginning of period $t$. For

$\overline{7}$ A related literature looks at private responses to public transfers (e.g., Moffitt (1992), Rosenzweig and Wolpin (1994), Jacoby (2002), and Jensen (2003)). Case and Deaton (1999a) point out that the impact of transfers might be different in the short and the long run, since it takes time for private behavioral responses to public transfers to have an effect. 
example, $A_{1}$ is a child's achievement as she enters school in period 1, and reflects only her family's investments in the previous period and her innate ability:

$$
A_{1}=g_{0}\left(F_{0}, \mu\right)
$$

where $g_{t}$ is a period-specific production function.

Upon enrollment, children's learning is also enhanced by the school inputs they receive each period, $S_{1}$ and $S_{2}$. Thus, a child's achievement at the start of the second year of school depends on endowments and the history of family and school inputs:

$$
A_{2}=g_{1}\left(S_{1}, F_{1}, F_{0}, \mu\right)
$$

Todd and Wolpin (2003) make a useful distinction between the amount of school inputs a child would receive if this were entirely up to her family, and the amount she actually receives at school. While families cannot control their children's school inputs, they can influence their level. In the U.S., for example, they can do this through residential choice or private schooling; in Romania, they might help their children prepare for transition exams. Let $\bar{S}_{t}$ denote the amount of inputs households target by such actions. Households choose this level as a function of their wealth and their children's endowment and achievement at the beginning of each period. For example:

$$
\bar{S}_{1}=\theta\left(A_{1}, W, \mu\right)
$$

Schools in turn can choose how to allocate resources to students. For example, a child making clear progress towards reading might receive less attention than a struggling one. Additionally, Todd and Wolpin cite that schools may use prior achievement to "track" students, a motivation relevant in our setting. Schools therefore have decision rules; e.g., they condition the inputs a child receives in period 1 on her achievement at the beginning of that period and on her endowment:

$$
S_{1}=\psi\left(A_{1}, \mu\right)
$$

With this, the deviation between the level of inputs children actually receive, and the amount their families had targeted for the first period is $\left(S_{1}-\bar{S}_{1}\right)$. Assume households observe this deviation before setting their own home input investment level. For example, for the first schooling period they use a decision rule: 


$$
F_{1}=\phi\left(A_{1}, W, \mu, S_{1}-\bar{S}_{1}\right)
$$

In words, a household sets its own investment for the first year of school as a function of its child's achievement at the beginning of the year, endowments, and the deviation between the school-based inputs they would want for their child and those she will actually receive (for instance, the child may not have been admitted to the school they had thought she would attend).

This simple setup illustrates the parameters that different types of work can identify. For example, a common goal of research is to answer the question: What would be the effect of exogenously changing the first period school input, $S_{1}$, say class size, while holding all other inputs constant?

$$
\frac{\partial A_{2}}{\partial\left(S_{1}-\bar{S}_{1}\right)}=\frac{\partial A_{2}}{\partial S_{1}}=\frac{\partial g_{1}}{\partial S_{1}}
$$

This is a question about the properties of the production function.

Todd and Wolpin argue that experiments more typically answer the question: What would be the total effect of an exogenous change in $S_{1}$, not holding other inputs constant. They refer to the STAR class size experiment as an illustration, since class size was manipulated exogenously but parents were free to adjust their own effort, for example. Such a policy effect is given by:

$$
\frac{d A_{2}}{d\left(S_{1}-\bar{S}_{1}\right)}=\frac{d A_{2}}{d S_{1}}=\frac{\partial g_{1}}{\partial S_{1}}+\frac{\partial g_{1}}{\partial F_{1}} \frac{\partial F_{1}}{\partial\left(S_{1}-\bar{S}_{1}\right)}
$$

This is a well-defined and interesting measure, one that in comparison to (2.1) also contains the indirect (behavioral) effect resulting from changes in parental investments. At the same time, it has some limitations; for example, cost benefit calculations might require ascertaining the relative contributions of school and family inputs. In addition it is worth noting that although in the present framework the behavioral response by parents is instantaneous, in real world situations it might take time for parents to notice and react to changes in school inputs. As a result, the estimated policy effect (2.2) could vary with the time at which child achievement is measured.

Now consider a second input such that there are two: $S_{1}^{x}$ and $S_{1}^{y}$. A randomized experiment might be able to vary one of these, say $S_{1}^{x}$, while controlling the level of the other. In that case the resulting impact will still resemble expression (2.2) This is broadly the way in which we interpret Duflo, Dupas, and Kremer (forthcoming). The setting allows the authors to manipulate the peer 
quality of the classes children have access to, while at the same time constraining changes to other school inputs. For example, teachers are randomly assigned to high or low achieving classes.

Now suppose the increase in $S_{1}^{x}$ originates not in an experiment but from an extensive and sustained policy. Then the school system will have a chance to react to this, and the total effect is:

$$
\frac{d A_{2}}{d\left(S_{1}^{x}-\bar{S}_{1}^{x}\right)}=\frac{d A_{2}}{d S_{1}^{x}}=\frac{\partial g_{1}}{\partial S_{1}^{x}}+\frac{\partial g_{1}}{\partial S_{1}^{y}} \frac{\partial S_{1}^{y}}{\partial S_{1}^{x}}+\frac{\partial g_{1}}{\partial F_{1}}\left(\frac{\partial F_{1}}{\partial\left(S_{1}^{x}-\bar{S}_{1}^{x}\right)}+\frac{\partial F_{1}}{\partial\left(S_{1}^{y}-\bar{S}_{1}^{y}\right)}\right)
$$

which differs from (2.2) in also including responses within the school system.

To summarize, Todd and Wolpin (2003) make a useful distinction between production function parameters (2.1) and policy effects (2.2). We wish to further emphasize that policy effects might be different in situations where behavioral responses take time to unfold, or where these responses only appear when certain interventions reach a certain scale-(2.3) versus (2.2). A further implication is that in the presence of behavioral responses, estimated policy effects are less likely to have external validity, since this also requires the indirect (behavioral) effects to be the same in another setting.

In short, aside from attempting to estimate the policy effect of having access to a better school, it is precisely the quantitative importance of the behavioral responses on the part of schools and parents - terms beyond the first one in the right hand side of equation (2.3) - that we attempt to uncover below.

\section{The student AlLocation mechanism}

The transition between middle and high school $\left(8^{\text {th }}\right.$ to $9^{\text {th }}$ grade) in Romania results in an unusually systematic and transparent allocation of students to schools. Specifically, every child who completes middle school receives a transition score which equally weights: ${ }^{8}$ i) her performance in a national $8^{\text {th }}$ grade exam covering Language, Math, and History/Geography, and ii) her gymnasium (grades 5-8) grade point average. ${ }^{9}$

After receiving their transition scores, students submit an essentially unlimited list of ranked choices which specify a combination of: i) a high school, and ii) one of seven academic tracks: Mathematics, Natural Sciences, Technical Studies, Services, Social Studies, Literature, and Natural

\footnotetext{
8 During the period we study, schooling in Romania was compulsory until the $10^{\text {th }}$ grade. As a result the entire cohort of students who complete middle school is required to participate in this allocation process.

9 All tests and grades use a scale ranging from 1 to 10 , with a passing grade of 5 . Students who score below 5 are not allowed to apply to high school, but can enroll in vocational school.
} 
Resources and Environmental Protection. ${ }^{10}$ These tracks constitute "schools within a school" in that the students in them take all their coursework together and do not take classes with members of other tracks - although they share infrastructure and a principal, meet during breaks, and might share teachers. Not all schools offer all tracks, and some schools offer more than one class per track, with class sizes subject to a cap.

Students' school/track choices are expressed through an application form submitted (through their gymnasium) to the Ministry of Education in the capital, Bucharest. Using a computerized system, the Ministry then allocates individuals into school/tracks, giving priority to higher scoring students and assigning them their most preferred choices until predetermined school/track capacity constraints bind. ${ }^{11}$ Schools submit their track-specific capacities to the Ministry in advance, and simply apply the admission lists returned from the capital. Under this set up (in contrast to many school choice schemes), students have incentives to truthfully reveal their preference rankings. ${ }^{12}$

Finally, when a school offers multiple classes of the same track, the system just returns to it the list of students admitted into the track, without further instructions on how to divide them into classes. We have data on this division for only a subset of schools (as detailed in the next section); these data and the anecdotal evidence suggest that many schools further stratify classes by ability.

\section{DATA}

We rely on two types of data: i) administrative information covering essentially the universe of children who make the middle to high school transition, and ii) data from a survey we administered in most towns with two or three high schools. ${ }^{13}$

\footnotetext{
${ }^{10}$ For the 2001 sample, the administrative data on tracks is not as precise; it combines three of the tracks (Technical Studies, Services, and Natural Resources and Environmental Protection) into one technical track.

${ }^{11}$ No criteria other than students' stated preferences and their transition scores are used in the allocation process; for example, there is no role for sibling preference or geographic proximity.

${ }^{12}$ Further, all students are required to make at least one active choice in the first round of the allocation process. However, some students only request school-track choices with minimum entry scores above their own transition scores. These individuals are assigned, in a second round process, to schools and tracks that did not fill in the first round. Students are warned against this outcome and the associated behavior is relatively rare. For example, in 2007 only 1.1 percent of the applicants were not allocated in the first round. On a related note, the existing legislation does not allow children to decline their initial assignment, although in rare situations children do manage to switch schools and/or tracks over the years. Such switching does not pose a threat to our research design, given that our "intent-to-treat" empirical strategy is based on the offered school choice.

${ }^{13}$ We use the term town to denote high school markets. The term that appears in the administrative data is locality (Localitate, in Romanian). In most cases these units actually correspond to cities/towns. In a few, they denote the largest of a number of small towns or villages - the town which actually contains the high school that might draw from a corresponding catchment area composed of smaller towns or villages. In all cases, these units should approximate self-contained (high school) educational markets.
} 
4.1. Administrative data. Our administrative data cover the 2001-2007 admission cohorts. They provide the name, gymnasium, transition score, and the allocated school/track for all students, but no information on their ranking of school/tracks or their socio-economic characteristics. We focus on two subsamples of these administrative data:

(1) The 2001-2003 cohorts, for which we linked admissions data with information on whether students took the Baccalaureate exam and how they performed (these cohorts took the exam in 2005-2007). ${ }^{14}$ As stated, a satisfactory Baccalaureate grade is a prerequisite for applying to university, and an excellent one essentially guarantees admission to the most prestigious institutions. ${ }^{15}$ These cohorts contain about 334,000 students attending about 800 high schools in 135 towns.

(2) The 2005-2007 cohorts, for which we have only admissions information and can thus only explore "first stages". This subsample consists of 301,000 students' originating in essentially the same schools and towns; it contains the students we surveyed, as described below.

Presenting descriptive statistics, Table 1 thus covers the universe of students admitted to high school during these years, with three exceptions. The first two reflect that, as explained below, we rank schools and set cutoff scores under the assumption that towns are self-contained markets. We therefore omit the capital, Bucharest, which is composed of six towns the borders of which students can cross with relative ease. We do not find this omission to affect our key conclusions. Second, when our analysis focuses on between-school cutoffs, we omit towns that have only one high-school. ${ }^{16}$ Finally, we drop all students who enroll in the vocational sector; this precludes their access to higher education and hence we do not observe Baccalaureate outcomes for them. ${ }^{17}$ After these exclusions, Table 1 presents summary statistics at the individual, track, school, and town level.

\footnotetext{
${ }^{14}$ We merged the admission and Baccalaureate data by student name and county using a fuzzy matching technique to allow for some misspelling of names. Our conclusions are not sensitive to different levels of precision in the matching algorithm, and are also similar if we restrict the analysis to exact matches. Our matched data do not allow us to differentiate between high school drop-outs and students who complete high school but do not take the Baccalaureate exam. Additionally, students are generally not allowed to take the Baccalaureate exam early, but those who fail the exam are allowed to retake it.

15 The Baccalaureate exam is a comprehensive test administered nationally. Students usually take six component exams, with a combination of common subjects (written language, oral language, written foreign language) as well as two track-specific exams and one elective exam. All the tests are graded on a scale from 1 to 10 and the overall Baccalaureate grade is the unweighted average of these scores.

${ }^{16}$ Despite these omissions, for simplicity we will describe the sample as covering "all towns" unless we focus only on those towns covered by our specialized survey.

${ }^{17}$ For analyses of vocational education in Romania, see Malamud and Pop-Eleches (forthcoming).
} 
4.2. Survey data. While the administrative data sets offer substantial sample sizes, they contain only basic information. To explore behavioral responses, we therefore carried out a survey that included principal, parent, and student questionnaires.

The way in which we carried out this survey partially explains our final survey sample, and we therefore begin with a brief description of its implementation. The 2005-2007 administrative data described above provided students' names, but not their addresses or any way of contacting them or their parents. The data also contained almost no information regarding school characteristics.

We therefore approached schools and asked their principals/administrators to fill a school survey, and to provide us with the addresses of the students in the mentioned cohorts (who were still in school at the time). The school survey collected information on the student population, and on school resources and infrastructure. The principals were also asked to provide a subjective ranking of their school-relative to other schools in their towns-along dimensions like teacher quality, student ability, and parental involvement. Our surveyors also collected administrative data on the experience, education and certification levels of the teachers responsible for seven subjects: Math, Romanian, History, Geography, Music, Sports and Computer Science. Each teacher was later matched to the students in the household survey based on who (by name) the students indicated were their teachers in these subjects.

During the first half of 2009, we used the list of addresses to directly approach parents and students at home. The survey we administered to them had three components. First, we interviewed the family to obtain demographic information on each member of the household, as well as basic household characteristics. Second, we surveyed the primary caregiver to elicit information on each child in the family. Third, we conducted a separate interview with the child from the selected school. Both the parental and the child surveys included questions on parent-child relationships, school performance and school experiences, an evaluation of the child's teachers, and a range of questions about child and family well being.

Two factors determined that we restricted our target sample to towns containing two or three schools. First, since we needed information from students on either side of admissions cutoffs, it was imperative that all schools in each town agree to participate, and therefore the effort was more likely to encounter problems in larger towns. Second, as shown below the administrative data reveal that the magnitude of the first stages is three to four times as large in smaller towns. We therefore 
started with an initial sample of 57,534 children and 167 schools in the 71 towns with two or three schools. If any school in a given town declined to participate, we simply abandoned the whole town.

In the event, we obtained complete school surveys and student data from 148 schools in 63 towns; the administrators in these schools provided us with 32,307 addresses. We restricted the target sample further to 138 schools in 59 towns, which contained 30,676 children. ${ }^{18}$ Due to financial constraints we randomly sampled 19,878 children (about 65 percent of the total) out of this population. From this target sample, we obtained 12,590 parent and child surveys. Our response rate of 63 percent, is in line with Gallup Romania's (the firm we contracted with) interview rate for this population. While the resulting sample is not completely representative of the population of these schools, we found no evidence that response rates differed between households whose children had a transition score just above a cutoff, and their counterparts who scored just below.

Table 2 presents descriptive statistics from the survey data, using the household and school questionnaires. We return to further discussion of its entries in the results section below.

\section{EMPIRICAL STRATEGY}

Although in principle a student can request any high school in the country, we suppose that students restrict their choices to the towns they live in, a reasonable assumption since the applicants are 13-14 year olds likely to still be living with their parents. Within each town, we rank schools and school/tracks (in separate exercises) according to their average score, and set the cutoffs equal to their minimum scores. ${ }^{19}$ In other words, we set each school's (or school/track's) cutoff equal to the transition score of the child that fills its last slot, where as stated the number of available slots are announced by schools prior to the admissions process.

This yields a large number of quasi-experiments - 1,984 if one considers schools; 6,434 if one considers school/tracks — since each cutoff score in our sample makes for a potential RD analysis. In this section we first discuss the conceptual basis for analyzing any given one of these experiments, focusing on schools for simplicity. We then describe how we go about summarizing them.

5.1. Empirical setup for a single between-school cutoff. Consider a town in which $i$ indexes students and $s=1, \ldots, S$ indexes schools, where the latter have been ordered from the worst to

${ }_{18}$ The elimination of four towns reflected that at least one school in each of them, though willing to fill out the school questionnaire, was unable to provide student addresses.

${ }^{19}$ We also implemented the exercise ranking schools and tracks by their minimum score, with quite similar results. 
the best in terms of the average transition score observed among their students. Additionally, let $z=1, \ldots,(S-1)$ index cutoffs, such that, for example $z=1$ denotes the cutoff between the worst and next-to-worst school in a town, and $z=(S-1)$ indicates the cutoff between the top-ranked school and the next best institution. Let $T_{i}$ stand for the average transition score among student $i$ 's peers (i.e., the average score among the children at her school), and let $t_{i}$ denote the student's own transition score. Finally, let $t_{z}$ be the minimum grade required for admission into the higher-ranked of the two schools indexed by $z$.

In this setup, consider the regression:

$$
T_{i}=\alpha 1\left\{t_{i} \geq t_{1}\right\}+a\left(t_{i}\right)+u_{i}
$$

where $1\left\{t_{i} \geq t_{1}\right\}$ is an indicator for whether a student's transition score is greater than or equal to the cutoff which determines access into the next-to worst school (cutoff $z=1$ ), and $a\left(t_{i}\right)$ is a flexible control function for the transition score. In this case, $\alpha$ estimates by how much students' peer groups improve, on average, when their score is just above rather than just below $t_{1}$.

The idea behind RD designs, originally proposed by Thistlewaite and Campbell (1960), is that discontinuities like those measured by $\alpha$ can be used to identify the causal effect of scoring above a cutoff even if students' transition scores are systematically related to factors that affect outcomes like Baccalaureate grades. ${ }^{20}$ Intuitively, suppose the transition score is smoothly related to characteristics that affect achievement. Under this assumption, students with scores just below $t_{1}$ will provide an adequate control group for individuals with scores just above, and any differences in their outcomes can be attributed to the fact that they have access to schools of different quality.

Specifically, one can run a reduced form regression analogous to (5.1) to explain outcomes like Baccalaureate performance, which we denote $Y_{i}$ :

$$
Y_{i}=\beta 1\left\{t_{i} \geq t_{1}\right\}+a\left(t_{i}\right)+v_{i}
$$

Again, if in a small enough neighborhood around the cut-off, $a(t)$ is constant, then the effect of achieving access to the next to worst school, $\beta$, is non-parametrically identified at $t_{1}$ (Hahn, Todd, and Van der Klaauw, 2001). More generally, if $a(t)$ is specified correctly, it will capture all dependence of the Baccalaureate grade on the transition scores away from the cut-off, and one can

${ }^{20}$ For an overview of the RD design, see Imbens and Lemieux (2008). 
use all the data to estimate (5.2). Below we will present such results, but also estimates that rely only on observations close to cutoff scores.

Finally, in addition to studying the impacts on Baccalaureate outcomes, we consider how a series of behaviors and/or characteristics on the part of students, parents, teachers, principals, and schools change as one crosses the cutoffs. For example, in a specification like (5.2), we ask if relative to children who score just below $t_{1}$, those who who score just above are more likely to have teachers who are certified, or parents who help with homework.

5.2. Summarizing information for many cutoffs. Specifications (5.1) and (5.2) explain how one might exploit one regression discontinuity — that arising from the hypothetical transition from the worst to the next-to worst school in a given town. In fact, as stated our data contain 1,984 such between-school cutoffs, and 6,434 between-track cutoffs. ${ }^{21}$ Below, we present information that exploits this wealth of quasi-experiments, exploring, for example, how the impact of scoring above a given cutoff varies with where in the transition test score distribution these cutoffs are located.

However, in order to summarize these data and for the sake of statistical power, we first report regressions in which we pool data across cutoffs. For this, we normalize each cutoff score, $z$, to zero, and create a variable that measures the distance between each cutoff and the transition score of each student in a town. In some cases we then "stack" the resulting data such that every student in a town serves as an observation for every cutoff, and (since individual level observations are used more than once) run the analyses clustering at the student level. ${ }^{22}$ Including all student observations for every cutoff is relevant in that, for example, the student with the best score in town could in principle attend any school she wanted. We note, however, that regressions restricted to students in bands close to the cutoffs in fact rarely use student-level observations more than once.

\section{Results}

This section first presents results that pool all the between-school and between-track cutoffs. It then turns to describing the heterogeneity in effects observed when discontinuities take place at

\footnotetext{
21 The between-school cutoffs are 663, 655, and 666 for the 2001, 2002, and 2003 entry cohorts, respectively; for the between-track cutoffs, the corresponding numbers are 1,956, 1,952, and 2,526.

22 To illustrate, in the first year of our data, 2001, the first town in our data, Alba-lulia, has 836 students in 7 schools, producing 6 between-school cutoffs. For that year, this produces a data set of $5,016\left(=836^{*} 6\right)$ observations, with similar calculations for the other two years of data.
} 
different points of the transition score distribution. Finally, it closes with exercises that, using our survey data, explore behavioral responses.

6.1. The first stage. Figure 1, Panel A illustrates the basic first stage result in our data, pooling all between-school cutoffs as described in Section 5. The x-axis describes students' transition scores relative to the cutoffs (normalized to zero) that allow the opportunity to access a better school; the y-axis describes the peer quality students experience, as measured by the mean transition score at their respective school. Panel A plots this mean transition score collapsed into cells containing individuals who are within 0.01 of a transition grade from each other. The right hand side Panel $\mathrm{B}$ plots analogous information, but the $\mathrm{y}$-axis is based on residuals from a regression of the mean transition score on a linear trend in students' transition grade and a series of cutoff fixed effects. ${ }^{23}$ Both panels suggest that the average peer quality students experience increases significantly and discontinuously if their transition score crosses the threshold that gives them the option of going to a better school. The vertical distance between the points close to the discontinuity, further, is analogous to the estimate of $\alpha$ in expression (5.1).

Table 3, Panel A presents the regression analog to these results, where columns 1-3 refer to all the towns in our sample. Panel A refers to the 2001-2003 admissions cohorts, those for which we have Baccalaureate outcomes. Column 1 uses about 3.6 million observations from 1,984 cutoffs observed across the three cohorts. It regresses the average transition grade that students experience at school on an indicator for whether their scores are above cutoffs. The specification includes: i) a linear spline in students' grade distance to the cutoffs, one which allows the slope to vary on each side of the cutoff, and ii) cutoff dummies analogous to those used in Figure 1, Panel B. ${ }^{24}$ The key estimate suggests that scoring above a cutoff results in a highly statistically significant jump in the peer quality students experience -0.09 points, which is equivalent to about 0.1 standard deviations in transition test performance.

Column 2 restricts the sample to include only students whose transition scores are within 1 point of a cutoff, reducing the number of observations to about half of those in Column 1. This is our preferred specification, as it attempts to balance the goal of focusing on observations close to the cutoffs while providing enough data to yield fairly precise estimates. We experimented with several

${ }^{23}$ Figures 1-9 all have a similar structure in that the left hand side panels use raw data, and the right hand side panels use residuals based on regressions that control for a linear trend in the transition grade and cutoff fixed effects. ${ }^{24}$ We note that these and all the following results are not qualitatively affected by instead using a linear, quadratic, or cubic specification for $a\left(t_{i}\right)$ in $(5.1)$, or by excluding the cutoff fixed effects. 
more stringent windows, with similar conclusions. ${ }^{25}$ We opt to feature, in Column 3, a regression within the bandwidths suggested by the procedure in Imbens and Kalyanaraman (2009) (henceforth IK), which in our data is generally more restrictive than the 1 point band used in Column $2 .{ }^{26}$ In the event, all these samples result in similar and highly significant estimates of $\alpha$.

Columns 4-6 repeat the specifications in columns 1-3 using the same administrative data, but focus only on towns included in our specialized survey-most towns with two or three schools, as described in Section 4. The corresponding graphical evidence for the survey towns is in Figure 2, panels $\mathrm{A}$ and $\mathrm{B}$. The observed discontinuities are always statistically significant, and about four times the size of those observed in the full sample.

The "first stages" in Table 3, Panel A are those that will be relevant for the Baccalaureate outcomes. ${ }^{27}$ They show that the Romanian high school admissions process provides a clear first stage for an RD analysis of the impact of having access to a better school, at least if school quality is judged by average transition scores. ${ }^{28}$ Below we will explore other dimensions along which school characteristics vary at the cutoffs.

Recall that in applying for high school slots students choose school/track combinations, and so the between-track cutoffs also provide candidate first stages. Figure 3 (panels A and B) present these using the same specifications as panels $\mathrm{A}$ and $\mathrm{B}$ in figures 1 and 2. The corresponding regression results are presented in panel B of Table 3. In all cases the coefficient of interest is somewhat smaller (although always statistically significant) than that observed for the between school cutoffs.

This is consistent with some sorting happening between-tracks within schools, with the implication being that students who just make it into a higher ranked school will indeed experience better peers, but that this will be more the case if the measure is the average score of their school-level rather than their track-level classmates. Panel $\mathrm{C}$ in Table 3 confirms this expectation, as it uses the track level average transition grade students experience as a dependent variable, and explores how

\footnotetext{
${ }^{25}$ For example, a previous version of the paper focused on only the administrative data (which offer substantial sample sizes) featured specifications that for each cutoff used only the two students immediately to the left and right. 26 Specifically, we follow Lee and Lemieux (forthcoming) and use a simple rectangular kernel. Further, we implemented the bandwidth selection procedure using the Stata ado file labeled rdob.ado available at http://www.economics.harvard.edu/faculty/imbens/software $\backslash$ imbens.

27 For the sake of space, we omit very similar results for the $2005-2007$ cohorts.

${ }^{28}$ Aside from first stage results like those described in Table 3, the RD approach requires that there be no discrete changes in other student characteristics that affect outcomes like Baccalaureate performance. While our administrative information does not contain such variables, our survey data suggest this condition is fulfilled. Specifically, Appendix Table A.1 shows that a number of background characteristics (mother's age, mother's ethnicity, mother's education, child age, and child gender) do not vary discontinuously around the grade cutoff once we consider estimates within 1 point and IK bandwidths (all but two of the nine estimates are also insignificant in the full sample).
} 
it changes at the cutoffs that determine access to a higher ranked school. The observed estimates are still highly significant, but as expected are smaller those observed when peer groups are defined at the school level (panel A).

In order to elaborate on how these first stage results originate, and because it is relevant for later interpretation, we note that while scoring above a cutoff gives students a chance to attend a better school, not all of them take up the opportunity. Specifically, panels A and B in (Appendix) Figure A.1 summarize information regarding the cutoffs that determine access to fairly selective schools, namely those that separate the best and second-best school (cutoff $z=S-1$ in the notation of Section 5) in towns that contain at least three schools. Panel A plots transition score cell means of the percentage of students who attend the best school, and not surprisingly this is equal to zero when students' scores are to the left of the cutoff-these students are not eligible to attend the most selective school in their town. While the proportion of students in the best school jumps discretely once one moves to the right, it does not rise to one; rather, roughly 40 percent of children eligible for enrollment in the best school take advantage of the opportunity. Panel B, which plots the percentage of individuals in the second best school, shows that about 25 percent of those eligible for the best decide to remain in the second-best school, with another 35 percent attending institutions other than the top two. ${ }^{29}$

Multiple factors (e.g. proximity) may account for why not all students take up the chance to go to the best school they are eligible for, an aspect we discuss further below. Whichever ones are actually operative, Figure A.1 underlines that results generated using the first stages in Table 3 should be interpreted in an "intent to treat" spirit. ${ }^{30}$

6.2. Baccalaureate outcomes. A first outcome we consider is simply whether students took the Baccalaureate exam. Panels C and D in Figure 1 present the graphical evidence for the 2001-2003 cohorts - the ones for which we have Baccalaureate data-and suggest few if any changes in testtaking rates at the cutoffs. This is confirmed in regressions in Panel A of Table 4, where columns 1-3 refer to the full sample of towns. The coefficient of interest suggests that getting the opportunity to go to a better school resulted in small and (except for the first specification) statistically insignificant

29 A related note is that all regressions exclude the child whose score was exactly equal to the cutoff, since that student may be selected. This reflects that this student's score dictates the cutoff score and, mechanically, that student attends the better school with probability one, which is empirically not the case with the individuals right above him or her. This exclusion does not have a qualitative effect on any of our conclusions.

${ }^{30}$ For further reference, panels C and D in Figure A.1 show analogous evidence for the cutoffs separating the worst and the next to worst schools in each town; panels $\mathrm{E}$ and $\mathrm{F}$ plot similar information for towns with only two schools. 
changes in the probability of taking the Baccalaureate exam. The results within bands allow us to rule out differences in test-taking rates of less than a third of a percentage point. In short, the opportunity to enroll in a better school does not seem to affect the likelihood that students take the Baccalaureate test.

A generally similar conclusion emerges among the towns in our survey sample (Figure 2, panels $\mathrm{C}$ and D and Table 4, Panel A, columns 4-6) and when we analyze the opportunity to enroll in a better track (Figure 3, panels C and D, and Table 4, panel C). ${ }^{31}$ This consistent lack of evidence of selection into test taking makes it easier to interpret effects on Baccalaureate performance.

Turning to this issue, panels $\mathrm{E}$ and $\mathrm{F}$ in Figure 1 describe grade outcomes at the cutoffs, suggesting a discrete increase in average achievement, particularly in Panel F. The corresponding regression evidence is in Panel B of Table 4, which presents statistically significant gains equivalent to about 0.02 to 0.10 standard deviations, depending on whether one looks at the full or the survey sample. ${ }^{32}$

The bottom line is that students who score above cutoffs giving them access to a better school perform better in the high stakes Baccalaureate exam, and under the assumptions underlying RD designs, this impact can be viewed as causal. A similar conclusion emerges when looking at the towns covered in our specialized survey (Figure 2, panels E and F, and Table 4, Panel B, columns 4-6), and when one considers between-track rather than between school cutoffs (Figure 3, panels E and F, and Table 4, Panel D). The magnitude of the effects on test performance is greatest in the survey towns, which is consistent with the larger first stage estimates observed there (Table 3).

6.3. Heterogeneity in Baccalaureate outcomes. The results presented thus far pool all between school and between track cutoffs. We now explore how the Baccalaureate effects vary according to where the cutoffs are located in the transition score distribution. To provide a visual summary of the results, Figure 4 presents evidence on the first stages observed in the top (panels A and B) and bottom terciles (panels $\mathrm{C}$ and $\mathrm{D}$ ) of between-school cutoffs if these were ordered according to the grades at which they happen. These panels reveal that the discontinuities in average peer quality are of a roughly similar magnitude in both sets of cutoffs. At a first pass level, students seem as interested in attending the best schools as they are in getting out of the worst.

\footnotetext{
${ }^{31}$ In contrast to Table 3, Table 4 no longer has columns 7-9. Again, this reflects that for the 2005-2007 cohorts we do not have Baccalaureate outcomes, so these variables are not available for the children we surveyed.

${ }^{32}$ As stated, if scaled by the peer improvements in Table 3, these estimates are of a magnitude similar to some observed in the literature on peer effects. To further explore this we could run instrumental variable-type specifications where peer quality is instrumented by students' position relative to the cutoff. We refrain from this, however, because as the results below show, many factors other than peer quality change at the cutoffs.
} 
Panels E-H present the graphical evidence on Baccalaureate performance. ${ }^{33}$ Specifically, panels $\mathrm{E}$ and $\mathrm{F}$ suggest that gaining admission to a better school-when the cutoff in question is in the top third of cutoffs - raises testing performance. Panels $\mathrm{G}$ and $\mathrm{H}$ point to a similar, if less precisely estimated effect among the bottom cutoffs.

Table 5 explores these and other points related to heterogeneity. For the sake of space, this table presents only specifications using observations within one point of the cutoffs, and focuses on the between-school cutoffs. To illustrate, Panel A refers to the full sample of cutoffs and repeats results presented above. Column 1 presents the first stage (from Table 3, Panel A, Column 2). Within Panel A, column 2 features the track level average transition score as a dependent variable, and columns 3 and 4 a dummy for taking the Baccalaureate exam, and performance on this test, respectively.

Within Table 5, panels B and C refer to the top and bottom tercile of cutoffs. Column 1 shows that the first stages are of about 30 percent larger for the top tercile. Comparing columns 1 and 2 confirms that as observed in the aggregate sample, when children get the opportunity to enroll in a better school, their track-level peer groups do not improve as much as their school-level peer groups. Turning to the heterogeneity in Baccalaureate effects, Column 3 shows that the lack of an effect on test taking persists in all the subsamples. The coefficients are never statistically significant at the five percent level, and are still generally suggestive of only small impacts on test taking rates.

In contrast, the estimates surrounding Baccalaureate performance (Column 4) generally suggest a positive impact from having the opportunity to attend a higher ranked school. The magnitude of the effect is larger and only significant in the top tercile, but cannot be clearly distinguished from that in the bottom tercile, which is itself statistically insignificant. ${ }^{34}$ The bottom line is that gaining access to a better school might be valuable to both high and low-scoring children, but statistical power constrains our ability to explore such heterogeneity. More generally, school effects are difficult to identify, and sample size issues alone might account for some of the variation in conclusions observed in the literature.

6.4. Behavioral responses. Using our survey of principals, parents, and children, we now investigate whether a major educational intervention like giving a child access to a better school (or

\footnotetext{
${ }^{33}$ We omit the evidence on test taking because there is again no evidence of an effect along this dimension.

${ }^{34}$ The two effects would be particularly difficult to tell apart in IV specifications which would account for the larger first stages in the top tercile.
} 
introducing tracking altogether) might lead to behavioral responses. It is important to note that our analysis does not attempt to determine to what extent specific factors (e.g., parents, teachers, or peers) account for the impact that attending a better school has on children's academic achievement. $^{35}$

To present results in this area, we make some notes on the structure of all remaining tables (6-11) and figures (5-9). In each table, Panel A aggregates outcomes to the school level; Panel B aggregates them to the track level, and Panel $\mathrm{C}$ presents them at the child or parent level. For example, in Table 6 one dependent variable is an indicator for whether Language teachers passed a certification exam. Panel A thus compares the children who scored just above a threshold with those who scored just below, and asks if on average their schools have more certified language teachers; Panel B asks if the tracks they are in are more likely to have certified teachers; Panel $\mathrm{C}$ asks if their own teacher is more likely to be certified. ${ }^{36}$ Note that the variables from the principal survey only vary at the school level, so Panels B and C are blank for them. As before, for each variable we present three specifications, where our preferred one is that restricted to individuals within one transition grade from the cutoff; we usually use these when discussing the results. Finally, here we focus only on the top cutoffs. Among our survey towns, this restriction is relevant only for those with three schools (19 of the 59 towns in the sample), as the two school towns of course contain only one cutoff. ${ }^{37}$

As above, in all figures the panels on the left hand side present simple means of the outcome variables, while the right hand side panels show fitted values of residuals from regressions of outcomes on a linear trend in transition scores and cutoff fixed effects. Since we have fewer observations in the survey data, the cells that we plot are within 0.05 of a transition score from each other. In each figure, panels A and B are aggregated to the school level, $\mathrm{C}$ and D to the track level, and E and F are at the student/parent level.

6.4.1. Teacher characteristics. Figure 5 and Table 6 describe the impact that scoring above a school cut-off has on the teacher characteristics that students experience. The first three columns of Table 6 show that students above the cutoff are about 13 percent more likely to attend a school which the

\footnotetext{
${ }^{35}$ Econometrically this would be hard to do without strong assumptions, given that we have one source of exogenous variation in the treatment (attending a better school), and many variables that might account for this effect (e.g., teacher, school, parent, and peer effects).

36 An individual student's outcome can be different from that observed in his track because some schools feature multiple classes within a track. Our survey asked each student for his or her Language teacher's name, and we used that to match students to teachers and teacher characteristics as supplied by the school based on administrative data. 37 This restriction reflects that the difference in peer quality between the bottom two schools in three school towns was small.
} 
principal declares has the best teachers in town. The remaining columns describe Language teacher qualifications as provided by their schools based on administrative records. ${ }^{38}$

The dependent variable in columns 4-6 is an indicator for whether teachers have attained the highest certification standard - a credential that about 60 percent of teachers in Romania have. Panel A shows that relative to those who just miss, students who score above a school cutoff attend schools where on average Language teachers are about 10 percent more likely to have reached this standard. Panel $\mathrm{B}$ shows this effect is reduced to about 3 percent when one looks at the tracks students are enrolled in. Panel $\mathrm{C}$ shows that the effect essentially disappears once one considers the actual teachers assigned to students - those just above a cutoff are not more likely to have a certified teacher than those just below.

This conclusion is also visible in Figure 5, where Panel A shows a sharp discontinuity in the school-level probability of Language teachers having the highest certification standard. Panel B shows significantly smaller discontinuities at the track level, and panel C suggests no discontinuity in terms of the actual teacher students encounter.

In short, in terms of teacher certification differences between schools exist on average, but these differences disappear when one considers the actual teachers experienced by students at the margin. This is consistent with teachers sorting both across and within schools in a way clearly associated with student stratification. For example, the pattern of results could reflect the highest certification teachers having a preference for-and through seniority gravitating towards - the highest academic ability children. Consistent with this columns 7-9 (Table 6) reveal a similar pattern when teacher quality is measured using years of experience.

However, it is worth noting that differences at the margin persist for some of our measures of teacher quality. Columns 10-12 show that attending a better school decreases the probability of having a "novice" teacher (one with two or fewer years of experience) not just on average, but also on the margin. ${ }^{39}$

6.4.2. Parental effort. Table 7 and Figures 6 and 7 describe the impact that being able to attend a better school has on measures of parental involvement and effort. We focus on measures of parents'

\footnotetext{
${ }^{38}$ We focus on Language teachers since all children in all tracks take this subject.

${ }^{39}$ On average teachers have about 15 years of experience, with only six percent having less than two years.
} 
participation at school and also on variables intended to capture their interactions with their own children, such as the willingness to help with homework or pay for tutoring services. ${ }^{40}$

The first six columns of Table 7 indicate that children above cutoffs attend schools where parents are on average more involved at school. This emerges both in principals' reports of parental participation (columns 1-3, Panel A) and in parents' self-reports on volunteering (columns 4-6, Panel A). However, the impacts at the track and individual level become small and statistically insignificant (columns 4-6, panels B and C). Figure 6 confirms that there is a discontinuity in parental volunteering at the school level, but not at the parent level. As was the case with teacher characteristics, this implies differences between the average and marginal parental effort: Children who score just above cutoffs have peers whose parents participate more at school, but their own parents do not participate more than those of children who score just below. A similar conclusion emerges in columns 7-9, where we use the frequency of parental expenditures on tutoring as the outcome variable.

However, there is evidence of parental behavioral responses in other dimensions. Table 7 considers the extent to which they help their children with homework. Columns 10-12 (Panel A) point to no differences at the cutoffs on the average likelihood that parents help on a daily or almost-daily basis. This might not be surprising given that the need for help might depend on children's academic ability. However, the most striking result is shown in Panel C, as well as in Panel F of Figure 7-a reduction in average parental help with homework for children just above cutoffs. This suggests that at least in our setting, parents might view their own effort and school quality as substitutes.

6.4.3. Interactions with peers. Section 6.1 showed that children who score above cutoffs are on average exposed to peers that have higher average transition scores. This first stage is confirmed and expanded upon by columns 1-3 of Table 8, which measure peer quality using principals' ranking of student quality among schools within their towns.

According to the often cited linear-in-means model, which assumes homogeneous treatment effects, these findings would imply positive peer effects for the children who make it into a better school. ${ }^{41}$ However, scoring above a cutoff could adversely impact children if their relative ability

\footnotetext{
40 To illustrate the variation in these dimensions, 11 percent of parents report that during the last year, they volunteered in their child's classroom, school office, or library. About 24 percent of parents report having paid for private tutoring lessons, a common practice in Romania. In addition, roughly 20 percent of parents claim to help with homework on a daily or almost daily basis. Finally, we note that secondary education is free in Romania; hence we do not consider tuition expenses as a measure of parental effort.

${ }^{41}$ Peer effects have been a focus in the educational literature, with a large number of papers attempting to empirically determine their presence and functional form (for instance, see Hoxby and Weingarth (2006), Lavy, Paserman, and Schlosser (2007), and Jackson (2010b)).
} 
ranking matters, since this makes them "a small fish in a big pond." Indeed, models which stress relative comparisons suggest negative effects through a reduction in confidence and/or self-esteem.

To explore this possibility, we first investigate whether children who score just above cutoffs actually perceive being lower in their peer ability distribution. Columns 4-6 explore this by running regressions in which children are asked about their rank within their track. The responses ranged from 1 to 7 with higher numbers indicating a better rank in terms of academic ability. Panels A-B in columns 4-6 show that on average children in better schools are more likely to feel they are strong relative to their peers, and as might be expected if they have over-optimistic views, the coefficient is positive rather than zero. More interestingly Panel $\mathrm{C}$ confirms that in contrast, children who score just above cutoffs rank themselves lower than those who score just below-the coefficients are negative (and also significant) in this case. This might not be surprising given that Romania's student allocation system is well understood by most students.

Finally we explore whether such feelings of inferiority are associated with the nature of children's interaction with their peers. We measure this using an index of negative interactions that averages four indicators for whether children report that, in the last month, their peers have: i) been mean to them, ii) hit them, iii) taken their things without asking, or iv) made them feel marginalized. The possible responses for each of these items ranged from zero (happened daily) to 5 (did not happen at all); the average of 4.87 across all four indicators suggests that these events are relatively rare. The results in Table 8 (columns 7-9) do not reveal average differences at the school level. However, the track and most importantly the individual level provide evidence of more frequent negative interactions for children who score just above cutoffs, a pattern confirmed by the graph in Panel F of Figure 8. In short, these results leave open the possibility that getting into a better school might result in feelings of insecurity or marginalization. It is also possible that the realization of such effects is behind the fact that not all students take up the opportunity to enroll in a more selective school (Figure A.1).

6.4.4. Student effort. Finally, we explore effort responses on the part of students. ${ }^{42}$ Our variables of interest are indicators for whether students did homework daily or almost daily in the month prior to the survey, an assessment of which our survey solicited from both parents and the children

${ }^{42}$ In results not reported in the paper, we have also explored how enrollment in higher-ranked school affects students' access to educational infrastructure. We find no significant differences in infrastructure availability at all three levels of aggregations, a result that holds for both principal and student reports. This is not a surprising outcome in Romania, where essentially all schools are public and in principle similarly equipped. 
themselves. The results are presented in the first six columns of Table 9, where Panel A suggests that students in better schools do more homework on average, suggesting higher effort in such settings. In this case this effect persists on the margin at least for the parental reports, which suggest a 5 percent increase in the probability of doing homework on a daily or almost daily basis. ${ }^{43}$ Finally, columns 7-9 show that while on average children at better schools perceive homework to be easier, the coefficient ceases to be statistically significant and changes sign at the margin, suggesting that, perhaps not surprisingly, marginal children encounter more difficulty with homework at higherranked schools - this may be yet another reason not all children attend the highest-ranked school they are eligible for.

6.5. Within track analysis. Thus far, we have focused on the reduced-form effects of having the chance to attend a better school or track within a school. This is a natural first approach given that students apply for high school/track combinations. In this section, we consider the effects of being able to enroll in a better class within a given track.

Specifically, the Ministry of Education stipulates that after students are admitted to a particular track within a school, they should be allocated to classes containing at most 28 students. ${ }^{44}$ In fact the track-specific slot availabilities which schools submit prior to the allocation process need to be multiples of 28. Since the Ministry does not specify how the allocation of students to classes within tracks is to be implemented, each school decides its own allocation. Our survey data suggest that many schools further stratify children into classes based on their transition scores. ${ }^{45}$

To estimate the effect of having access to a better class (within a track), we focus only on tracks which had slot offerings that were multiples of 28 (i.e. 56, 84, 112, etc.), and which were also completely filled at the time of the admission process. ${ }^{46}$ We ranked the students in these tracks in descending order based on their transition scores, and calculated class level cutoff scores based on the transition score of the $28^{\text {th }}$ (or $56^{\text {th }}$ or $84^{\text {th }}$, etc.) student. As above, we normalized the transition scores relative to the cutoffs, and stacked the data by keeping, on each side of a particular

\footnotetext{
${ }^{43}$ The results on children's homework effort are confirmed graphically in Figure 9.

${ }^{4}$ After being allocated to a particular class, students usually spend the next four years with the same peers, taking all subjects together.

${ }^{45}$ In anecdotal evidence, our conversations with headmasters confirm that many schools have this policy.

${ }^{46}$ As mentioned earlier, our identification strategy is based on the fact that the majority of schools reach their pre-announced capacity constraint. At the same time, it is worth mentioning that enrollment in many of the less desirable schools is often less than the number of initial slot offerings.
} 
cutoff, the 28 students within a track with scores closest to the cutoff. Also as above, our analysis focuses on intent to treat estimates of scoring above a particular class level cutoff. ${ }^{47}$

Understanding these effects is interesting for two reasons. First, by looking at children in different classes but in the same track, we are able to make comparisons between children who are exposed to the same curriculum. These results therefore provide a robustness check for our school and track level analysis, in which we cannot control for potential curriculum differences. Second, considering classes allows us to analyze behavioral responses in a setting that even more closely approximates the experimental setting of Duflo, Dupas, and Kremer (forthcoming), where an RD analysis compares students who are on the margin of being assigned to low or high achieving classes.

Table 10 presents the results at the class (Panel A) and child or parent level (Panel B). For variables that do not vary within classes, such as class-level peer quality or teacher qualifications, the results in both panels are identical and are therefore presented only once. Column 1 begins by illustrating the "first stage" showing that there is a clear discontinuity in classroom peer quality at the class cutoffs. An increase of 0.13 points in the average transition emerges from a regression using observations within 1 point of the transition score cutoffs. Although the effect is highly significant, its magnitude is about half the size of the track-based estimates, and about one fourth the size of the school-based estimates. This reflects that there is significantly less variability in the transition scores between classes within school/tracks.

Columns 2-4 (Table 10) consider the same teacher characteristics examined in Table 6 . The evidence suggests that teacher sorting is also prevalent across classes in a school/track. Students who score above a class cutoff are exposed to teachers who are 5 percent more likely to have the highest certification and have 1.8 more years of experience. ${ }^{48}$

The remaining columns present all the other outcome variables featured in our previous analysis of the survey data (measures of parental participation, children's interaction with peers, and child homework effort) with results that are qualitatively similar to those found in Tables 7-9. For example, although the parent of the child who just makes it into a better class is not more likely to pay for tutoring services, this child is more likely to be exposed to peers whose parents buy such services. At the same time, several key coefficients in this table, especially the marginal

\footnotetext{
47 Again, while not every school in our sample allocates children to classes based only on the transition score, as long as a fraction of schools do so, we can estimate the effects of being able to attend a better class within a track.

48 The small and insignificant result on novice teachers (Column 4) is not surprising given the results in Table 6, which suggested no difference in this dimension across tracks.
} 
effects in Panel B, are imprecisely estimated, which could be explained both by the smaller sample sizes and the fact that the differences in educational environments (as seen in Column 1) are less stark than in the school or track level analysis. Nevertheless, the bottom line is that many of the behavioral responses we observed previously - particularly the sorting of more qualified teachers to better classes - can also be observed across classes within the same track.

6.6. Effects across cohorts. Finally, we investigate whether the behavioral responses identified have a dynamic component: For example, do students' responses emerge only gradually during their high school years? This matters because such dynamics suggest that the estimated effects of experimental or quasi-experimental analyses may vary depending, for example, on when in students' careers post-test scores are collected.

For the sake of space, Table 11 focuses only on specifications including students within one transition score point of the cutoffs. For reference, Panel A repeats specifications at the student level from previous tables. For example, the dependent variable in Column 2 is the Language teacher experience measured in years. The coefficient (-0.625) is from Table 6, Column 8, Panel C, and shows there is no change (at the cutoff) in the experience of the teacher students experience.

Panel B explores whether these effects vary with time by looking at how they change across the three entry cohorts we surveyed: 2005, 2006, and 2007. This comparison allows us to explore if there are differences according to whether students are in their second, third, or fourth year of high school. This is achieved by including an indicator for whether students' transition scores were above the cutoff and interacting this dummy with indicators for the 2005 and 2006 cohorts, such that the first coefficient refers to the 2007 (the youngest) cohort.

The results contain some interesting variation. For example, columns 6 and 7 suggest that children's feelings of academic inferiority, and the frequency of their negative interactions with peers, are more marked in earlier stages of high school. This might not be surprising to the extent that the transition scores contain noise, and therefore the children ranked lowest upon entry are unlikely to on average turn in the worst performance during the year. As this information is revealed students' self assessment their and peers perceptions might change, affecting behavior.

Similarly, the reductions in parental help with homework happen early on and are partially reversed by the senior year. Specifically, in column 5 the key coefficient is significant for the youngest 
cohort (2007), but the joint test for the oldest cohort (2005) is not statistically significant (pvalue $=0.29)$. This might be consistent, for example, with parents gradually realizing that their child's admission into a better school might not eliminate the need for support on their part. Consistent with this, Column 4 shows that while the parents of children who just make it into more selective schools are not more likely to invest in tutoring in the second year of high school, by the fourth they are in fact more likely to do so. If tutoring indeed raises academic achievement (e.g. Banerjee, Cole Duflo, and Linden, 2007) then this effect might contribute towards finding school effects by the fourth but not the second year. Finally, columns 2 and 3 show less evidence of variation across cohorts in terms of teacher characteristics.

To summarize, we also find evidence that in Romania some of the behavioral responses identified above have a dynamic component. This is relevant, for example, because it implies that the estimated effects of going to a better school might depend on whether academic outcomes are measured at the $9^{\text {th }}$ or $12^{\text {th }}$ grade level.

\section{Conclusion}

In fields ranging from Labor to Development Economics, distinct interest surrounds the impact of educational quality on individual outcomes. This impact has not been fully established mainly because it is difficult to find situations in which otherwise comparable students enroll in schools of different quality.

In this paper, our first contribution has been to address this obstacle by analyzing Romania's educational system, which allocates students to high schools in one of the most systematic procedures observed around the world. This mechanism yields a large number of RD-based quasi-experiments, and has enabled us to contribute to the literature with unusually large sample sizes and an exploration of the heterogeneity in effects at different points of the test score distribution. Our second contribution has been to implement a specialized survey in a subset of towns, and to use the resulting data to explore behavioral responses and equilibrium effects that arise when a child has the opportunity to attend a better school-in this case in a school system where children are stratified by ability.

Our first reduced form result is that access to a better school has a positive impact on cognitive outcomes as measured by a high-stakes exam. This result has not been a consistent finding in the 
literature, as some papers — including some which also rely on an RD approach — find little indication that enrolling in a higher-achievement school or class raises learning.

Our second set of results provides evidence of significant behavioral responses and equilibrium effects. Specifically, we find that teachers sort in response to the stratification of students, such that an individual who just makes it into a more selective school is assigned a teacher who is less qualified than the average instructor at the school, and possibly no different than the teacher she would have encountered at the school she just avoided. This teacher sorting may be an equilibrium outcome that has developed over time in this stratified school system. Similarly, while children who make it into a better school encounter greater average parental participation, there is little evidence that their own parents increase their commitment to education, and in fact there is some indication that they reduce the extent to which they help with homework. Along the same lines, while children who make it into better schools are exposed to better peers, they also seem to realize they are weaker and to feel marginalized. For the behavioral responses by parents and children, we also provide evidence that these effects have a dynamic component - the estimates depend on how many years the child has attended a particular school.

While the magnitude or even the direction of these responses may reflect institutions that are specific to Romania, their existence suggests that (perhaps as one would expect) educational markets are sophisticated arenas in which several agents interact. As a result, the causal mechanisms that link any given school input to outcomes like wages or learning are likely to be complicated.

This has implications regarding the experimental evaluation of educational interventions. This research typically relies on partial equilibrium experiments that attempt to hold constant factors including responses like those explored here; additionally, it often measures outcomes in the short run. If dynamic behavioral responses are relevant, however, then the very nature (and impact) of a given intervention may change as actors have a chance to respond. Further, some of these responses may only be observed when an intervention is taken to scale and sustained. These possibilities amplify the usual concerns regarding small scale experiments' external validity.

More broadly, our findings imply that educational interventions and educational institutions should be analyzed with reference to how their design affects the behavior of different agents involved in the educational process. This point is explored theoretically in recent work including MacLeod and Urquiola (2009), Das et al. (2010), and Albornoz, Berlinski, and Cabrales (2010)). 


\section{REFERENCES}

Acemoglu, D. (2010): "Theory, general equilibrium, and political economy in development economics," Journal of Economic Perspectives, 24(3), 17-32.

Albornoz, F., S. Berlinski, and A. Cabrales (2010): "Incentives, resources, and the organization of the school system," Mimeo, University College, London.

Banerjee, A., S. Cole, E. Duflo, and L. Linden (2007): "Remedying Education: Evidence from Two Randomized Experiments in India," Quarterly Journal of Economics, 122(3), 12351264.

BanerJee, A., And E. Duflo (2008): "The experimental approach to development economics," Discussion Paper 14467, National Bureau of Economic Research.

BECKeR, G. (1964): Human capital: A theoretical and empirical analysis, with special reference to Education. University of Chicago Press, Chicago.

(1981): A treatise on the family. Harvard University Press, Cambridge.

Becker, G., And N. Tomes (1986): "Human capital and the rise and fall of families," Journal of Labor Economics, 4, S1-S39.

Behrman, J., S. Khan, D. Ross, and R. Sabot (1997): "School quality and cognitive achievement production: A case study for rural Pakistan," Economics of Education Review, 16(2), 127142.

Brown, P. (2006): "Parental education and child learning: Human capital investments in time and money," Economic Development and Cultural Change, 54(4).

Case, A., and A. Deaton (1999a): "Large cash transfers to the elderly in South Africa," Economic Journal, 450, 1330-1361.

(1999b): "School inputs and educational outcomes in South Africa," Quarterly Journal of Economics, 114(3), 1047-1084.

Clark, D. (forthcoming): "Selective schools and academic achievement," B.E. Journal of Economic Analysis and Policy: Advances.

Cullen, J., B. JacoB, and S. LevitT (2006): "The effect of school choice on student outcomes: Evidence from randomized lotteries," Econometrica, 74(5), 1191-1230.

Dale, S. B., And A. B. Krueger (2002): "Estimating the payoff to attending a more selective college: An application of selection on observables and unobservables," Quarterly Journal of Economics, 117(4), 1491-1527.

Das, J., S. Dercon, J. Habyarimana, K. Muralidharan, V. Sundararaman, and P. KrISHNAN (2010): "When can school inputs improve test scores?," Mimeo, University of California at San Diego.

DeAton, A. (2010): "Instruments, randomization, and learning about development," Journal of Economic Literature, 48, 424-455.

Duflo, E., P. Dupas, and M. Kremer (forthcoming): "Peer effects, teacher incentives, and the impact of tracking: Evidence from a randomized evaluation in Kenya," American Economic Review, pp. 1395-1435.

Hahn, J., P. Todd, and W. van DER KlaAuW (2001): "Identification and estimation of treatment effects with regression discontinuity design," Review of Economic Studies, 69(1), 201-209.

Hastings, J., T. Kane, and D. Staiger (2009): "Heterogeneous Preferences and the Efficacy of Public School Choice," Mimeo, Brown University.

Hoekstra, M. (2009): "The effect of attending the flagship state university on earnings: A discontinuity-based approach," Review of Economics and Statistics, 91(4), 717-724.

Hoxby, C., and G. Weingarth (2006): "Taking race out of the equation: School reassignment and the structure of peer effects," mimeo, Harvard Universtiy. 
Imbens, G., and K. Kalyanaraman (2009): "Optimal bandwith choice for the regression discontinuity estimator," Mimeo, Harvard University.

Imbens, G., and T. Lemieux (2008): "Regression discontinuity designs: A guide to practice," Journal of Econometrics, 142(2), 615-635.

JACKSON, C. K. (2010a): "Do students benefit from attending better schools?: Evidence from rule based student assignments in Trinidad and Tobago," The Economic Journal.

_ (2010b): "Peer quality or input quality? Evidence from Trinidad and Tobago," Working Paper 16598, National Bureau of Economic Research.

JACOBY, H. (2002): "Is there an educational intrahousehold 'flypaper effect'? Evidence from a school feeding program," The Economic Journal, 112, 196-221.

Jensen, R. (2003): "Do Private Transfers 'Displace' the Benefits of Public Transfers? Evidence from South Africa," Journal of Public Economics, 88, 89-112.

Krueger, A. (1999): "Experimental Estimates of Education Production Functions," Quarterly Journal of Economics, 114(2), 497-532.

LANkFord, H., S. Loeb, And J. Wyckoff (2002): "Teacher sorting and the plight of urban schools: A descriptive analysis," Educational Evaluation and Policy Analysis, 24(1), 37-62.

Lavy, V., M. D. Passerman, and A. Schlosser (2007): "Inside the black box of ability peer effects: Evidence from variation in high and low achievers in the classroom," Mimeo, Hebrew University.

LeE, D., And T. Lemieux (Forthcoming): "Regression discontinuity designs in Economics," Journal of Economic Literature.

MacLeod, W. B., and M. Urquiola (2009): "Anti-lemons: School reputation and educational quality," Working paper no. 15112, National Bureau of Economic Research.

Malamud, O., and C. Pop-Eleches (forthcoming): "General education versus vocational training: Evidence from an economy in transition," Review of Economics and Statistics.

Moffitt, R. (1992): "Incentive effects of the U.S. welfare system: A review," Journal of Economic Literature, 30, 1-60.

Park, A., X. Shi, C.-T. Hsieh, and X. An (2008): "Does School Quality Matter?: Evidence from a Natural Experiment in Rural China," Mimeo, University of Chicago.

RosenzWeig, M., and K. Wolpin (1994): "Transfers to young women and their children," American Economic Review, 84, 1195-1212.

SAAVEDRA, J. (2009): "The learning and early labor market effects of college quality: A regression discontinuity analysis," Mimeo, Harvard University.

SEKHRI, S., AND Y. Rubinstein (2010): "Do public colleges in developing countries provide better education than private ones? Evidence from general education sector in India," Mimeo, University of Virginia.

Thistlewaite, D., and D. Campbell (1960): "Regression discontinuity analysis: An alternative to the ex-post facto experiment," Journal of Educational Psychology, 51(6), 309-317.

TODD, P., AND K. WolPin (2003): "On the specification and estimation of the production function for cognitive achievement," The Economic Journal, 113, F2-F33. 
Figure 1: Between-school cutoffs, all towns
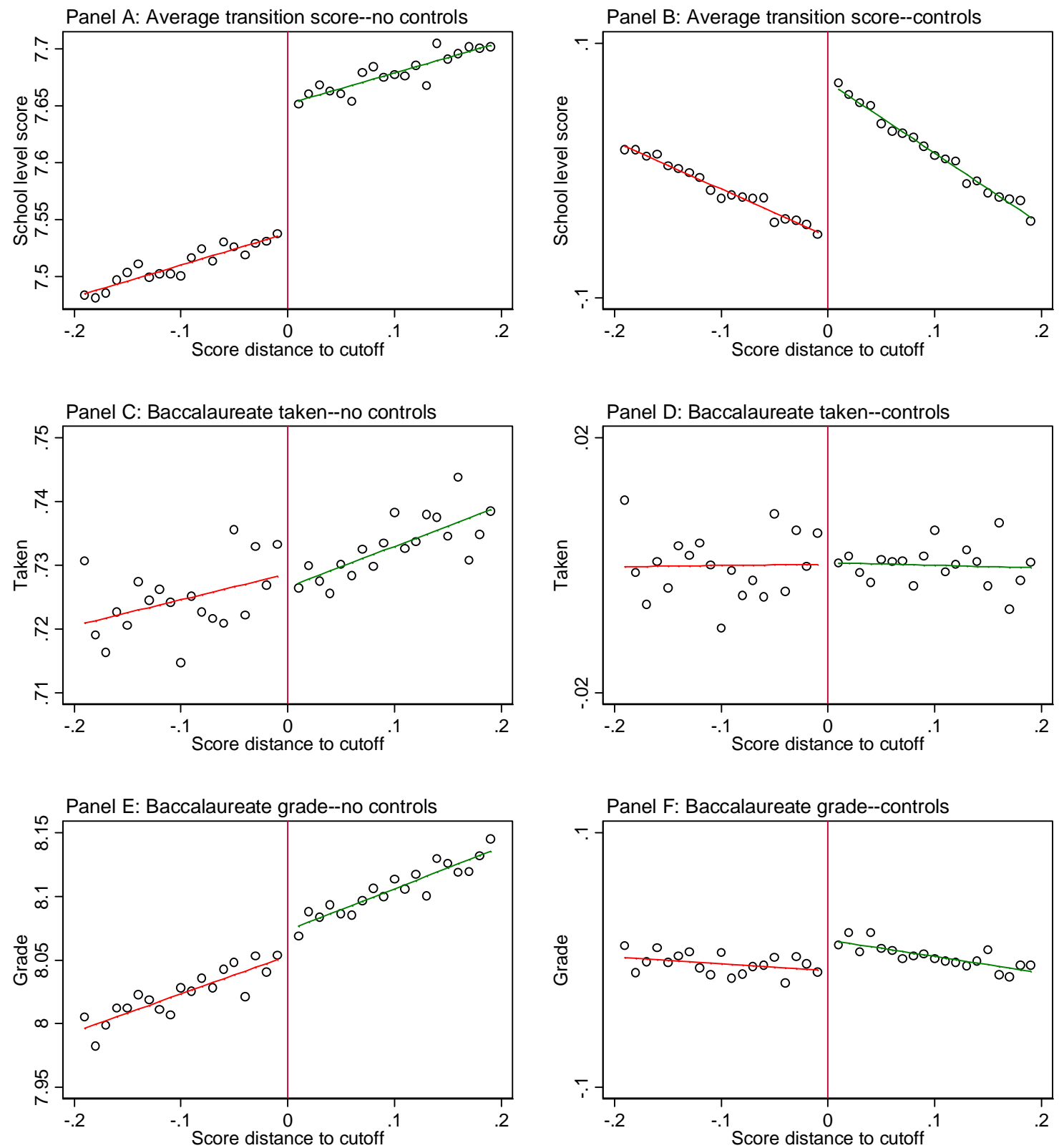

Note: All panels are based on administrative data for the 2001-2003 admission cohorts, and restrict observations to individuals with transition scores within 0.2 points of a cutoff (normalized to zero in all cases). The left hand side panels plot ( 0.01 point) transition score cell means of the dependent variable. The right hand side panels plot analogous means of residuals from a regression of the dependent variable on a linear trend in the transition score and cutoff fixed effects. In each panel, the solid lines are fitted values of regressions of the dependent variable on a linear trend in the transition score, estimated separately on each side of the cutoff. The dependent variable in panels A and B is the average transition score of the peers students encounter at school; the dependent variable in panels $\mathrm{C}$ and $\mathrm{D}$ is an indicator for having taken the Baccalaureate test; the dependent variable in panels $\mathrm{E}$ and $\mathrm{F}$ is the Baccalaureate exam grade. 
Figure 2: Between-school cutoffs, survey sample towns
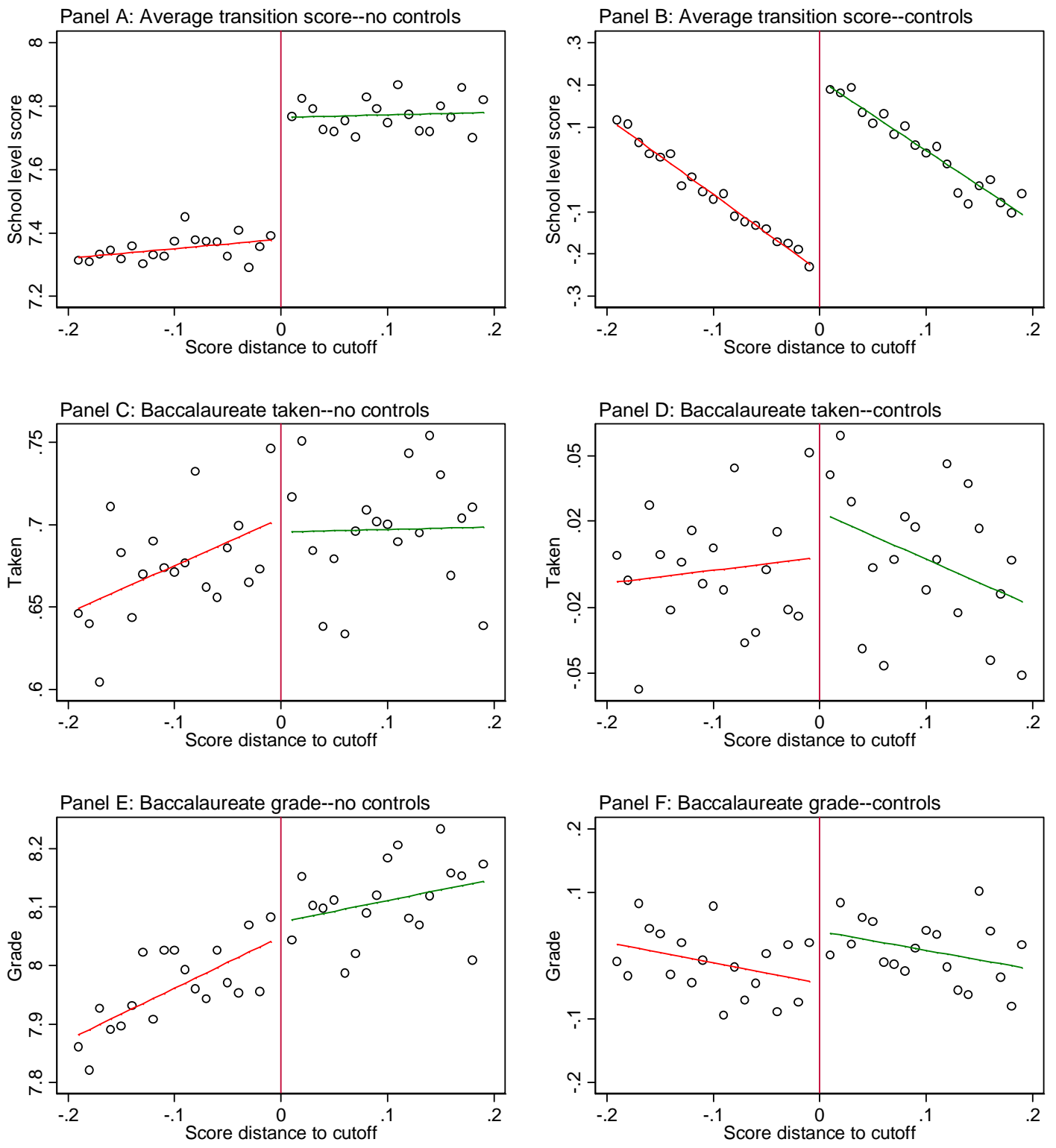

Note: All panels are based on administrative data for the 2001-2003 admission cohorts, and restrict observations to individuals with transition scores within 0.2 points of a cutoff (normalized to zero in all cases). The left hand side panels plot ( 0.01 point) transition score cell means of the dependent variable. The right hand side panels plot analogous means of residuals from a regression of the dependent variable on a linear trend in the transition score and a cutoff fixed effects. In each panel, the solid lines are fitted values of regressions of the dependent variable on a linear trend in the transition score, estimated separately on each side of the cutoff. The dependent variable in panels A and B is the average transition score of the peers students encounter at school; the dependent variable in panels $\mathrm{C}$ and $\mathrm{D}$ is an indicator for having taken the Baccalaureate test; the dependent variable in panels $\mathrm{E}$ and $\mathrm{F}$ is the Baccalaureate exam grade. 
Figure 3: Between-track cutoffs, all towns
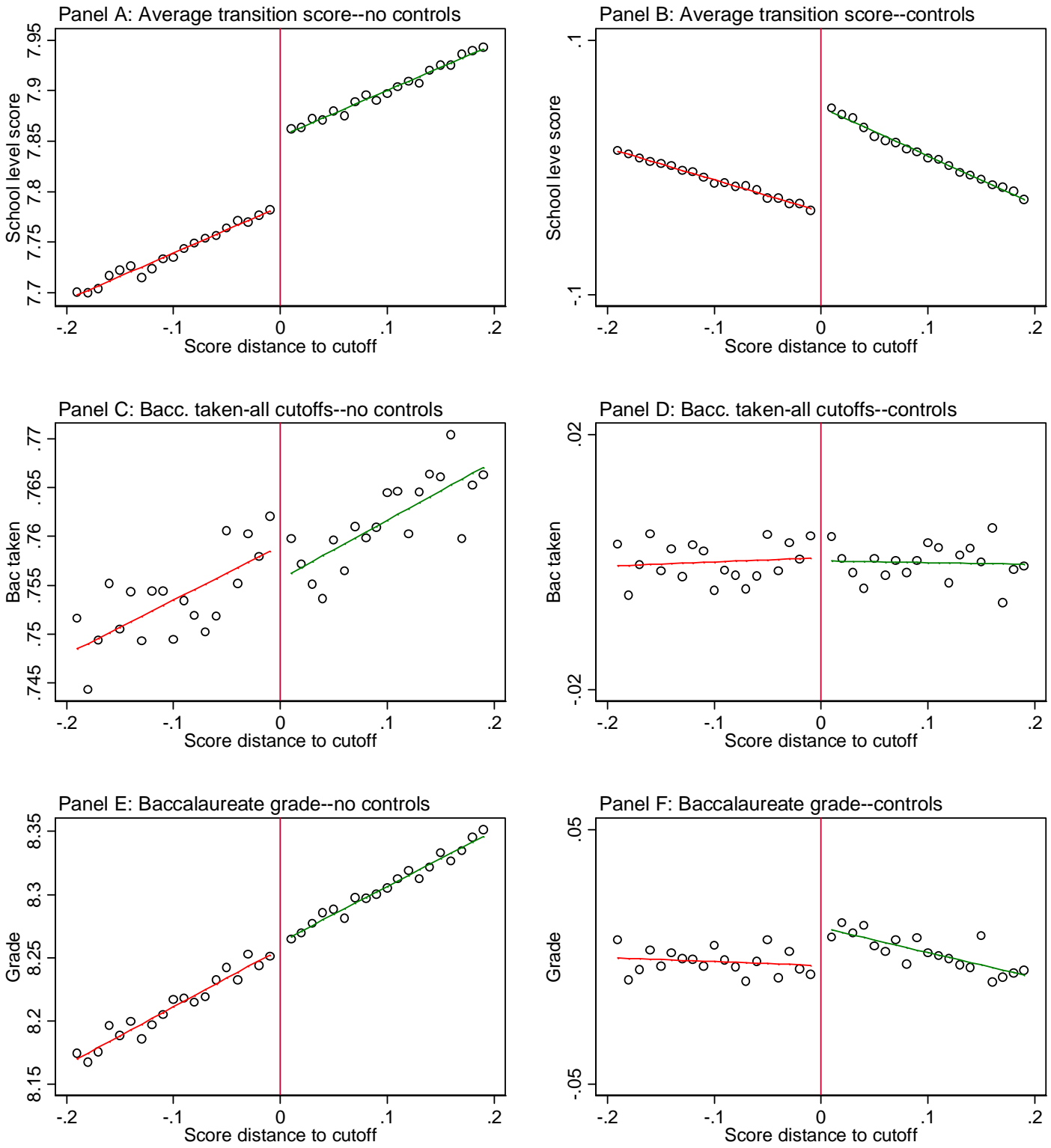

Note: All panels are based on administrative data for the 2001-2003 admission cohorts, and restrict observations to individuals with transition scores within 0.2 points of a cutoff (normalized to zero in all cases). The left hand side panels plot ( 0.01 point) transition score cell means of the dependent variable. The right hand side panels plot analogous means of residuals from a regression of the dependent variable on a linear trend in the transition score and cutoff fixed effects. In each panel, the solid lines are fitted values of regressions of the dependent variable on a linear trend in the transition score, estimated separately on each side of the cutoff. The dependent variable in panels A and B is the average transition score of the peers students encounter at school; the dependent variable in panels $\mathrm{C}$ and $\mathrm{D}$ is an indicator for having taken the Baccalaureate test; the dependent variable in panels $\mathrm{E}$ and $\mathrm{F}$ is the Baccalaureate exam grade. 
Figure 4: Top and bottom terciles of between-school cutoffs
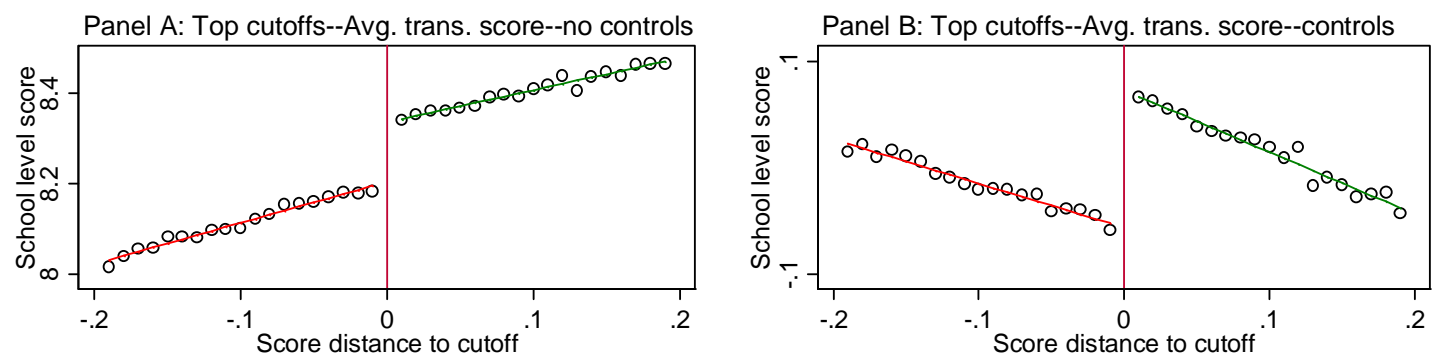

Panel C: Bottom cutoffs--Avg. trans. score--no control

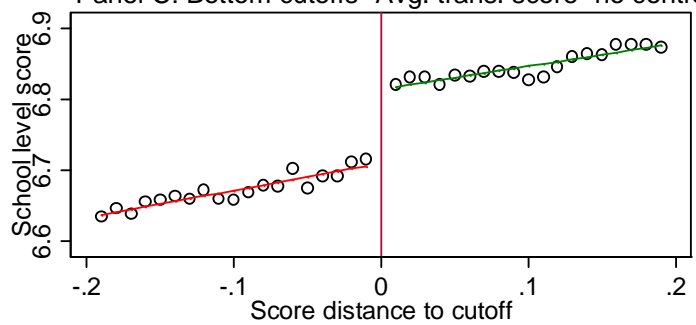

Panel D: Bottom cutoffs--Avg. transition score--controls
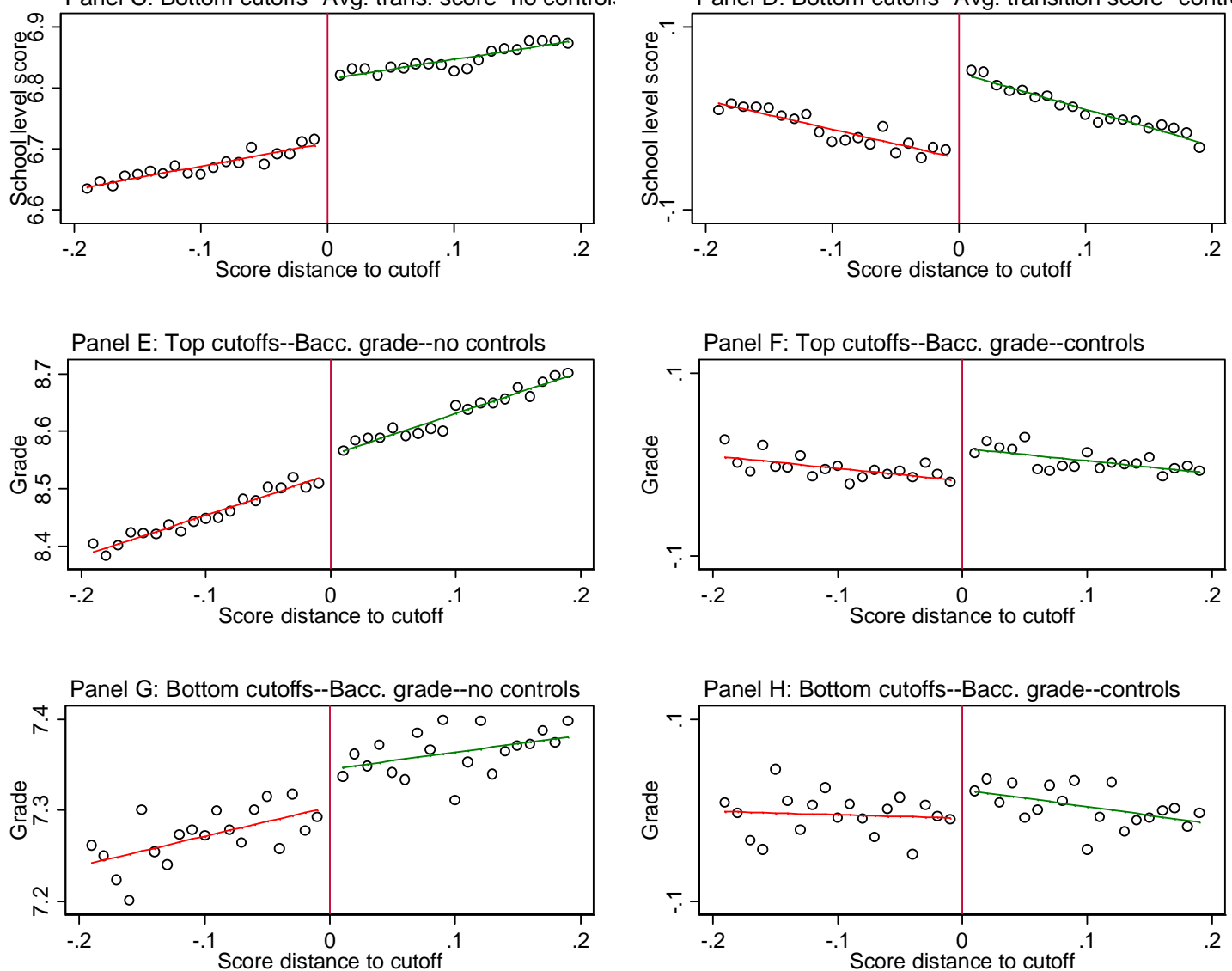

Note: All panels are based on administrative data for the 2001-2003 admission cohorts, and restrict observations to individuals with transition scores within 0.2 points of a cutoff (normalized to zero in all cases). The left hand side panels plot ( 0.01 point) transition score cell means of the dependent variable. The right hand side panels plot analogous means of residuals from a regression of the dependent variable on a linear trend in the transition score and cutoff fixed effects. In each panel, the solid lines are fitted values of regressions of the dependent variable on a linear trend in the transition score, estimated separately on each side of the cutoff. Panels A, B, E and F refer to the top tercile of between-school cutoffs ordered by the scores at which they take place; panels $\mathrm{C}, \mathrm{D}, \mathrm{G}$, and $\mathrm{H}$ to the bottom tercile. The dependent variable in panels A-D is the average transition score of the peers students encounter at school; the dependent variable in panels E-H is the Baccalaureate exam grade. 
Figure 5: Teacher certification
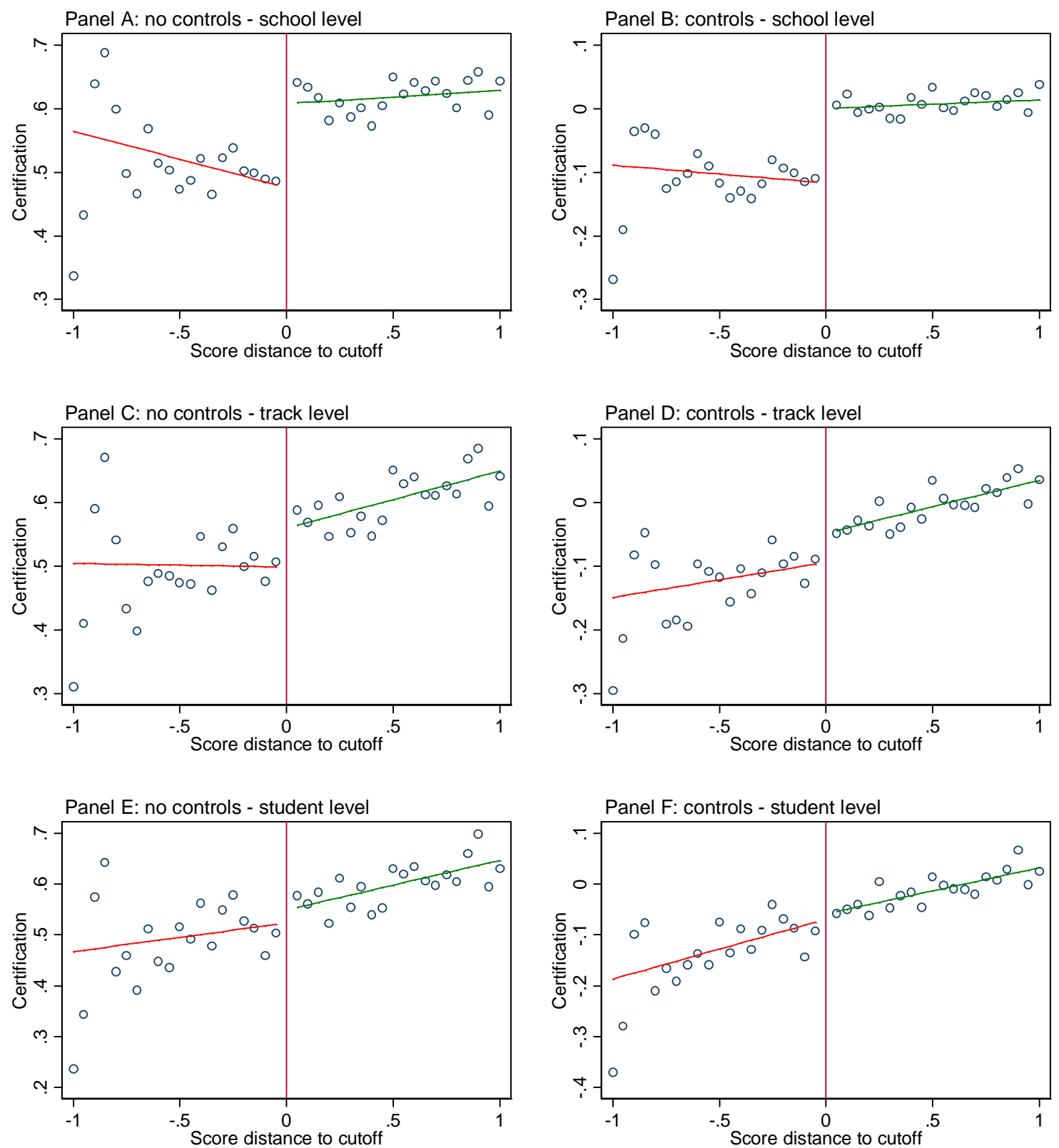

Note: All panels are based on survey data for the 2005-2007 admission cohorts, and restrict observations to individuals with transition scores within 1 points of a cutoff (normalized to zero in all cases). The left hand side panels plot ( 0.05 point) transition score cell means of an indicator for whether teachers have attained the maximum certification standard. The right hand side panels plot analogous means of residuals from a regression of the dependent variable on a linear trend in the transition score and cutoff fixed effects. The solid lines are fitted values of regressions of the dependent variable on a linear trend in the transition score, estimated separately on each side of the cutoff. Panels A and B present the outcome variable aggregated to the school level, and panels C and D present it aggregated to the track level. Panels E and F present the outcome variable at the child or parent level. 
Figure 6: Parental volunteering at school
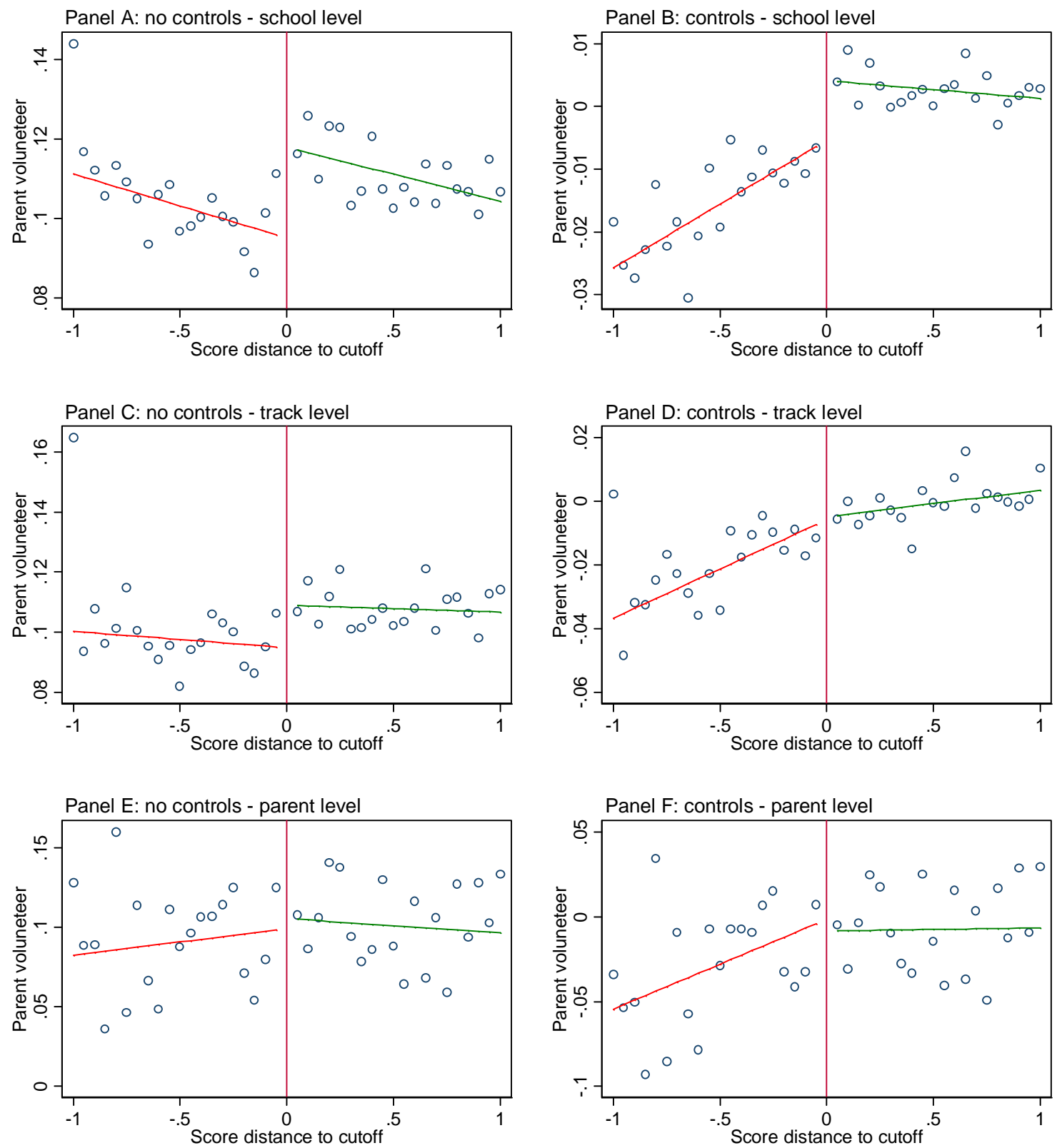

Note: All panels are based on survey data for the 2005-2007 admission cohorts, and restrict observations to individuals with transition scores within 1 points of a cutoff (normalized to zero in all cases). The left hand side panels plot ( 0.05 point) transition score cell means of an indicator for whether parents have volunteered at school in the past year. The right hand side panels plot analogous means of residuals from a regression of the dependent variable on a linear trend in the transition score and cutoff fixed effects. The solid lines are fitted values of regressions of the dependent variable on a linear trend in the transition score, estimated separately on each side of the cutoff. Panels A and B present the outcome variable aggregated to the school level, and panels $\mathrm{C}$ and D present it aggregated to the track level. Panels E and F present the outcome variable at the child or parent level. 
Figure 7: Parental help with homework
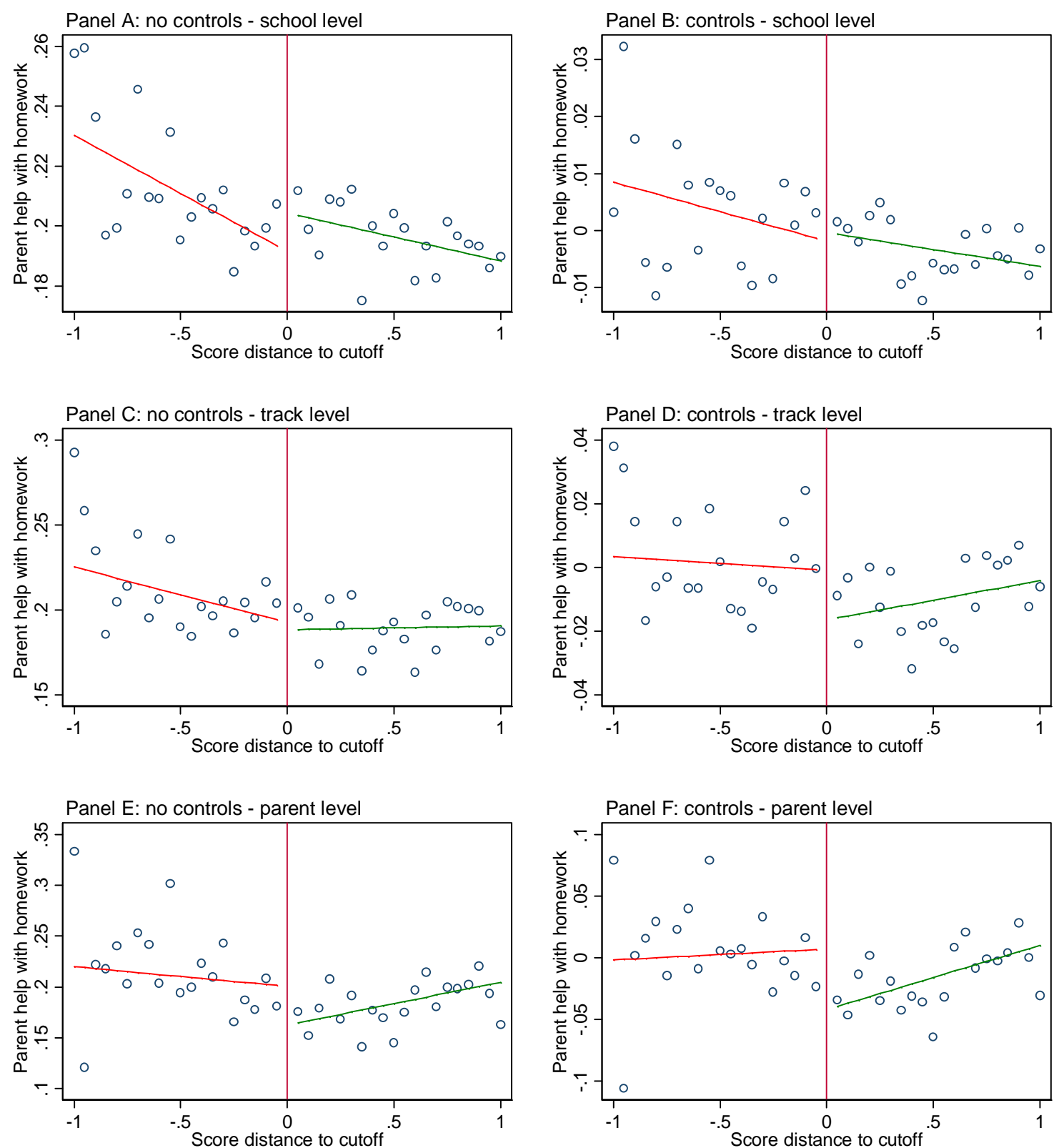

Note: All panels are based on survey data for the 2005-2007 admission cohorts, and restrict observations to individuals with transition scores within 1 points of a cutoff (normalized to zero in all cases). The left hand side panels plot ( 0.05 point) transition score cell means of an indicator for whether, in the month before the survey, parents declare helping their children with homework on a daily or almost daily basis. The right hand side panels plot analogous means of residuals from a regression of the dependent variable on a linear trend in the transition score and cutoff fixed effects. The solid lines are fitted values of regressions of the dependent variable on a linear trend in the transition score, estimated separately on each side of the cutoff. Panels A and B present the outcome variable aggregated to the school level, and panels C and D present it aggregated to the track level. Panels E and F present the outcome variable at the child or parent level. 
Figure 8: Negative interaction with peers at school
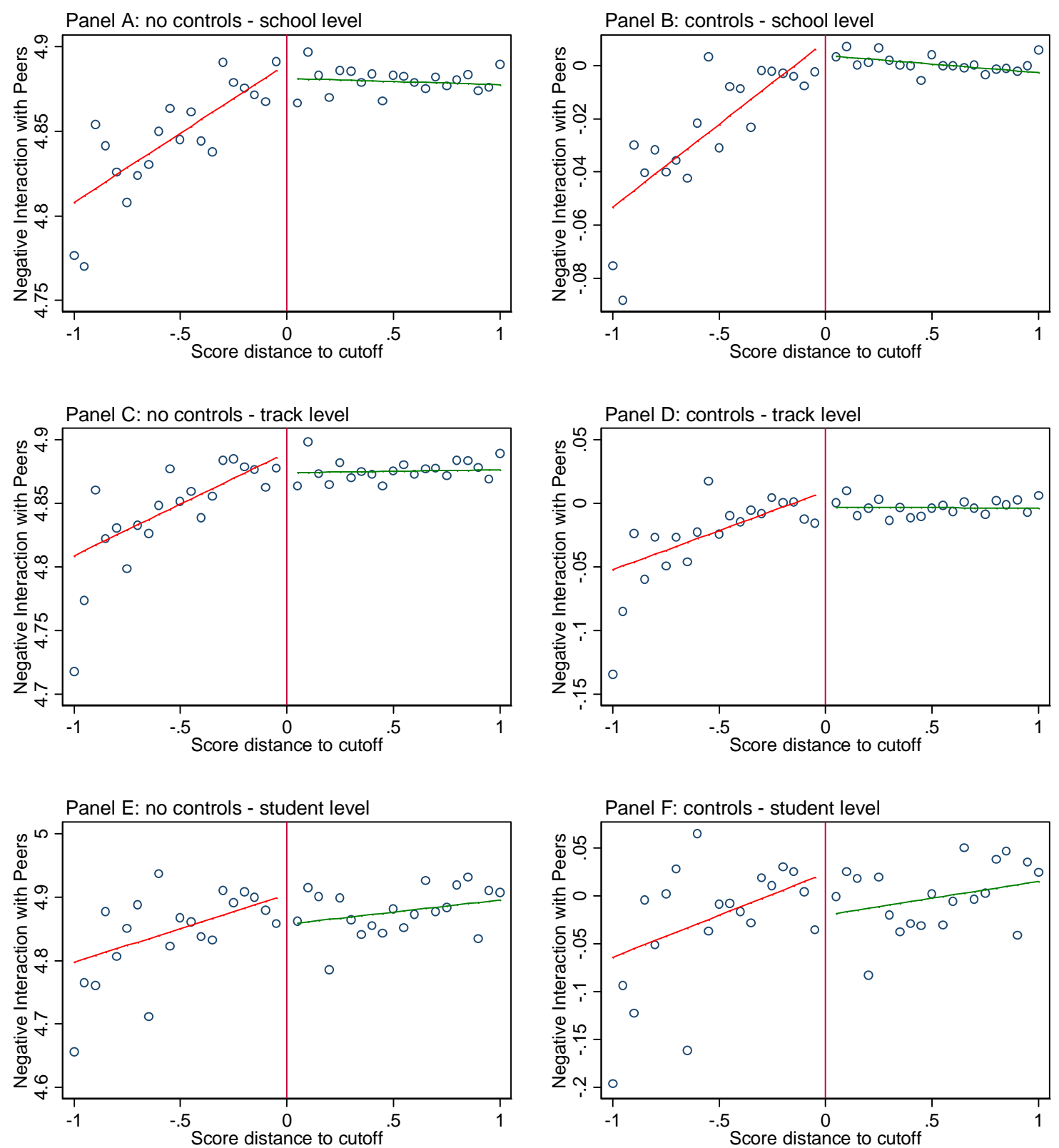

Note: All panels are based on survey data for the 2005-2007 admission cohorts, and restrict observations to individuals with transition scores within 1 points of a cutoff (normalized to zero in all cases). The left hand side panels plot ( 0.05 point) transition score cell means of an index of children's negative interactions with peers at school (Section 4). The right hand side panels plot analogous means of residuals from a regression of the dependent variable on a linear trend in the transition score and cutoff fixed effects. The solid lines are fitted values of regressions of the dependent variable on a linear trend in the transition score, estimated separately on each side of the cutoff. Panels A and B present the outcome variable aggregated to the school level, and panels C and D present it aggregated to the track level. Panels E and F present the outcome variable at the child or parent level. 
Figure 9: Children's homework effort (parental report)
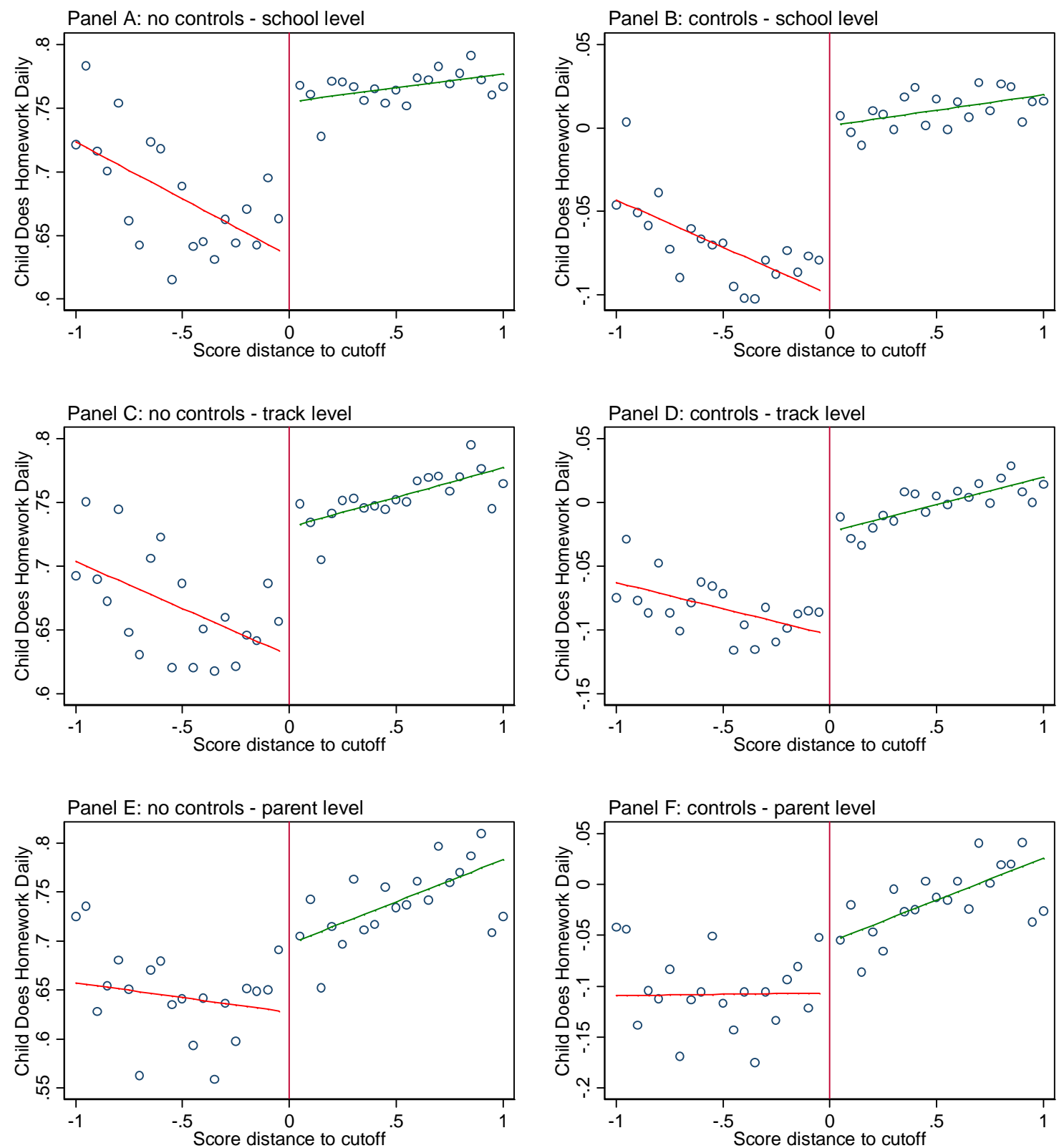

Note: All panels are based on survey data for the 2005-2007 admission cohorts, and restrict observations to individuals with transition scores within 1 points of a cutoff (normalized to zero in all cases). The left hand side panels plot ( 0.05 point) transition score cell means of an indicator for whether, based on parental reports, children do homework on a daily or almost daily basis. The right hand side panels plot analogous means of residuals from a regression of the dependent variable on a linear trend in the transition score and cutoff fixed effects. The solid lines are fitted values of regressions of the dependent variable on a linear trend in the transition score, estimated separately on each side of the cutoff. Panels A and B present the outcome variable aggregated to the school level, and panels $\mathrm{C}$ and $\mathrm{D}$ present it aggregated to the track level. Panels E and F present the outcome variable at the child or parent level. 
Table 1: Descriptive statistics, administrative data

\begin{tabular}{|c|c|c|c|c|c|c|c|c|c|c|c|c|c|c|c|}
\hline \multirow[b]{3}{*}{ Panel A.1: Individual le } & \multicolumn{15}{|c|}{ High school admis sion cohort } \\
\hline & \multicolumn{5}{|c|}{2001} & \multicolumn{5}{|c|}{2002} & \multicolumn{5}{|c|}{2003} \\
\hline & & & & & & & & & & & & & & & \\
\hline Baccalaureate taken & 0.847 & 0.360 & 0 & 1 & 107,812 & 0.822 & 0.383 & 0 & 1 & 110,912 & 0.809 & 0.393 & 0 & 1 & 115,413 \\
\hline Baccalaureate grade & 8.31 & 0.93 & 5.19 & 10.00 & 87,411 & 8.28 & 0.95 & 5.18 & 10.00 & 85,946 & 8.51 & 0.88 & 5.27 & 10.00 & 84,110 \\
\hline \multicolumn{16}{|l|}{ Panel A.2: Track level } \\
\hline 9th grade enrollment & 135.3 & 61.4 & 2 & 352 & 797 & 140.6 & 63.1 & 9 & 420 & 789 & 144.1 & 69.2 & 3 & 432 & 801 \\
\hline Number of tracks & 2.2 & 1.2 & 1 & 5 & 797 & 2.1 & 1.2 & 1 & 5 & 789 & 2.0 & 1.2 & 1 & 5 & 801 \\
\hline \multicolumn{16}{|l|}{ Panel A.4: Town level } \\
\hline 9th grade enrollment & 804.6 & 849.6 & 62 & 3,819 & 134 & 827.7 & 875.5 & 60 & 4,088 & 134 & 854.9 & 919.5 & 45 & 4,169 & 135 \\
\hline No. of schools & 5.9 & 6.0 & 2 & 29 & 134 & 5.9 & 5.8 & 2 & 28 & 134 & 5.9 & 5.9 & 2 & 29 & 135 \\
\hline No. of tracks & 12.9 & 11.9 & 2 & 58 & 134 & 12.4 & 11.4 & 2 & 56 & 134 & 12.0 & 10.9 & 2 & 52 & 135 \\
\hline Transition grade & 8.14 & 0.80 & 6.50 & 9.64 & 105,737 & 8.26 & 0.76 & 6.41 & 9.67 & 98,647 & 8.39 & 0.77 & 3.68 & 9.74 & 97,069 \\
\hline Baccalaureate taken & $\mathrm{n} / \mathrm{a}$ & $\mathrm{n} / \mathrm{a}$ & $\mathrm{n} / \mathrm{a}$ & $\mathrm{n} / \mathrm{a}$ & $\mathrm{n} / \mathrm{a}$ & $\mathrm{n} / \mathrm{a}$ & $\mathrm{n} / \mathrm{a}$ & $\mathrm{n} / \mathrm{a}$ & $\mathrm{n} / \mathrm{a}$ & $\mathrm{n} / \mathrm{a}$ & $\mathrm{n} / \mathrm{a}$ & $\mathrm{n} / \mathrm{a}$ & $\mathrm{n} / \mathrm{a}$ & $\mathrm{n} / \mathrm{a}$ & $\mathrm{n} / \mathrm{a}$ \\
\hline Baccalaureate grade & $\mathrm{n} / \mathrm{a}$ & $\mathrm{n} / \mathrm{a}$ & $\mathrm{n} / \mathrm{a}$ & $\mathrm{n} / \mathrm{a}$ & $\mathrm{n} / \mathrm{a}$ & $\mathrm{n} / \mathrm{a}$ & $\mathrm{n} / \mathrm{a}$ & $\mathrm{n} / \mathrm{a}$ & $\mathrm{n} / \mathrm{a}$ & $\mathrm{n} / \mathrm{a}$ & $\mathrm{n} / \mathrm{a}$ & $\mathrm{n} / \mathrm{a}$ & $\mathrm{n} / \mathrm{a}$ & $\mathrm{n} / \mathrm{a}$ & $\mathrm{n} / \mathrm{a}$ \\
\hline \multicolumn{16}{|l|}{ Panel B.2: Track level } \\
\hline 9th grade enrollment & 62.8 & 47.8 & 1 & 308 & 1,684 & 60.4 & 44.3 & 1 & 280 & 1,634 & 59.1 & 42.4 & 3 & 252 & 1,644 \\
\hline \multicolumn{16}{|l|}{ Panel B.3: School level } \\
\hline 9th grade enrollment & 129.4 & 70.6 & 2 & 420 & 817 & 120.3 & 64.8 & 1 & 336 & 820 & 116.8 & 62.2 & 3 & 308 & 831 \\
\hline Number of tracks & 2.1 & 1.2 & 1 & 5 & 817 & 2.0 & 1.2 & 1 & 5 & 820 & 2.0 & 1.2 & 1 & 5 & 831 \\
\hline \multicolumn{16}{|l|}{ Panel B.4: Town level } \\
\hline 9th grade enrollment & 766.2 & 839.8 & 45 & 3,767 & 138 & 720.1 & 764.6 & 46 & 3,650 & 137 & 683.5 & 728.5 & 57 & 3,462 & 142 \\
\hline No. of schools & 5.9 & 6.0 & 2 & 32 & 138 & 6.0 & 6.2 & 2 & 34 & 137 & 5.9 & 6.0 & 2 & 33 & 142 \\
\hline No. of tracks & 12.2 & 11.4 & 2 & 58 & 138 & 11.9 & 11.2 & 2 & 60 & 137 & 11.6 & 10.9 & 2 & 59 & 142 \\
\hline
\end{tabular}

Note: This table describes data covering the universe of Romanian towns with two exceptions (discussed in Section 4): i) towns that make up Bucharest, and ii) towns that contain a single school. Panel A.1 presents student level statistics for the 2001-2003 cohorts. Panels A.2, A.3, and A.4 refer to characteristics at the track, school, and town level, respectively. Panels B.1-B.4 present analogous information for the 2005-2007 cohorts. 
Table 2: Descriptive statistics, survey data

\begin{tabular}{|c|c|c|c|}
\hline & Mean & Std. Dev. & $\mathrm{N}$ \\
\hline \multicolumn{4}{|l|}{ Panel A: Socioeconomic characteristics (Household survey) } \\
\hline Female head of household & 0.112 & 0.316 & 11,931 \\
\hline Age of household head & 46.752 & 7.145 & 11,843 \\
\hline \multicolumn{4}{|l|}{ Ethnicity of household head } \\
\hline Romanian & 0.938 & 0.240 & 11,931 \\
\hline Hungarian & 0.050 & 0.218 & 11,931 \\
\hline Gypsy & 0.003 & 0.056 & 11,931 \\
\hline Other & 0.008 & 0.091 & 11,931 \\
\hline \multicolumn{4}{|l|}{ Education of household head } \\
\hline Primary & 0.665 & 0.472 & 11,840 \\
\hline Secondary & 0.205 & 0.404 & 11,840 \\
\hline Tertiary & 0.130 & 0.337 & 11,840 \\
\hline Female Child & 0.584 & 0.493 & 11,931 \\
\hline Age of Child & 18.077 & 0.939 & 11,866 \\
\hline \multicolumn{4}{|l|}{ Panel B: Parental responses (Household survey) } \\
\hline Parent has volunteered at school in the past 12 months & 0.111 & 0.314 & 11,868 \\
\hline Parent has paid for tutoring services in the past 12 months & 0.237 & 0.425 & 11,850 \\
\hline Parent helps child with homework every day or almost every day & 0.197 & 0.398 & 11,815 \\
\hline Child does homework every day or almost every day & 0.752 & 0.432 & 11,779 \\
\hline \multicolumn{4}{|l|}{ Panel C: Child responses (Household survey) } \\
\hline Relative rank among peers ( $1-7$, with 7 better ranked) & 4.745 & 1.300 & 11,798 \\
\hline Index of negative interactions with peers ${ }^{1}$ & 4.879 & 0.369 & 11,838 \\
\hline Child does homework every day or almost every day & 0.632 & 0.482 & 11,908 \\
\hline Child perceives homework to be easy (1-7, with 7 easiest) & 5.450 & 1.015 & 9,628 \\
\hline \multicolumn{4}{|l|}{ Panel D: Language teacher qualifications } \\
\hline Proportion of teachers with highest state certification & 0.608 & 0.488 & 11,169 \\
\hline Years of experience & 15.801 & 12.228 & 11,169 \\
\hline Proportion of teachers who are "novices" (less than 2 years of experience) & 0.061 & 0.238 & 11,169 \\
\hline
\end{tabular}

Notes: This table describes a specialized survey collected in 135 schools among 59 towns for the 20052007 admissions cohorts (see Section 4).

${ }^{1}$ Index based on the sum of four indicators for whether, during the past month, children's peers: i) were mean to them, ii) hit them, iii) took their things without asking, or iv) made them feel marginalized. Each indicator ranges between 0 (happened daily) and 5 (did not happen in the past month). 
Table 3: First stages

\begin{tabular}{|c|c|c|c|c|c|c|c|c|c|}
\hline \multirow[t]{3}{*}{ Dependent variable: } & \multicolumn{6}{|c|}{ Administrative data } & \multirow{2}{*}{\multicolumn{3}{|c|}{ Survey data }} \\
\hline & \multicolumn{3}{|c|}{ All towns } & \multicolumn{3}{|c|}{ Survey towns } & & & \\
\hline & $\begin{array}{c}\text { Full } \\
\text { sample } \\
(1) \\
\end{array}$ & $\begin{array}{c}\text { Within } \\
1 \text { point } \\
\text { of cutoff } \\
(2)\end{array}$ & $\begin{array}{l}\text { Within } \\
\text { IK } \\
\text { bound } \\
(3) \\
\end{array}$ & $\begin{array}{l}\text { Survey towns } \\
\text { sample } \\
\text { (4) }\end{array}$ & $\begin{array}{c}\text { Within } \\
1 \text { point } \\
\text { of cutoff } \\
(5)\end{array}$ & $\begin{array}{c}\text { Within } \\
\text { IK } \\
\text { bound } \\
(6)\end{array}$ & $\begin{array}{c}\begin{array}{c}\text { Full } \\
\text { sample }\end{array} \\
\quad(7) \\
\end{array}$ & $\begin{array}{c}\text { Within } \\
1 \text { point } \\
\text { of cutoff } \\
(8)\end{array}$ & $\begin{array}{c}\text { Within } \\
\text { IK } \\
\text { bound } \\
(9)\end{array}$ \\
\hline \multicolumn{10}{|c|}{$\overline{\text { Panel A: School-level avg. transition grade - 2001-2003 cohorts - between school cutoffs }}$} \\
\hline $1\{$ Trans. grade $\geq$ Cutoff $\}$ & $\begin{array}{r}0.094 \\
(0.001)\end{array}$ & $\begin{array}{r}0.107 \\
(0.001)\end{array}$ & $\begin{array}{r}0.115 \\
(0.001)\end{array}$ & $\begin{array}{c}0.454^{* * *} \\
(0.005)\end{array}$ & $\begin{array}{l}0.446^{* * *} \\
(0.007)\end{array}$ & $\begin{array}{l}0.447^{* * *} \\
(0.007)\end{array}$ & & & \\
\hline Linear spline & Yes & Yes & Yes & Yes & Yes & Yes & & & \\
\hline $\mathrm{R}^{2}$ & 0.817 & 0.790 & 0.792 & 0.729 & 0.754 & 0.754 & & & \\
\hline $\mathrm{N}$ & $3,609,572$ & $1,857,376$ & $1,160,458$ & 64,052 & 39,363 & 39,104 & & & \\
\hline \multicolumn{10}{|c|}{ Panel B: Track-level avg. transition grade - 2001-2003 cohorts - between track cutoffs } \\
\hline $1\{$ Trans. grade $\geq$ Cutoff $\}$ & $\begin{array}{r}0.067 \\
(0.001)\end{array}$ & $\begin{array}{r}0.063 \\
(0.001)\end{array}$ & $\begin{array}{r}0.065 \\
(0.001)\end{array}$ & $\begin{array}{r}0.203 \\
(0.003)\end{array}$ & $\begin{array}{l}0.188^{* * *} \\
(0.003)^{2}\end{array}$ & $\begin{array}{l}0.187^{* * *} \\
(0.003)\end{array}$ & & & \\
\hline Linear spline & Yes & Yes & Yes & Yes & Yes & Yes & & & \\
\hline $\mathrm{R}^{2}$ & 0.873 & 0.857 & 0.857 & 0.779 & 0.792 & 0.793 & & & \\
\hline $\mathrm{N}$ & $8,802,699$ & $4,845,812$ & $4,400,772$ & 265,896 & 172,656 & 154,366 & & & \\
\hline \multicolumn{10}{|c|}{ Panel C: Track-level avg. transition grade - 2001-2003 cohorts - between school cutoffs } \\
\hline $1\{$ Trans. grade $\geq$ Cutoff $\}$ & $\begin{array}{r}0.068 \\
(0.001)\end{array}$ & $\begin{array}{r}0.073 \\
(0.001)\end{array}$ & $\begin{array}{r}0.082 \\
(0.001)\end{array}$ & $\begin{array}{r}0.283 \\
(0.005)\end{array}$ & $\begin{array}{l}0.266 \\
(0.006)\end{array}$ & $\begin{array}{l}0.266^{* * * *} \\
(0.006)\end{array}$ & & & \\
\hline Linear spline & Yes & Yes & Yes & Yes & Yes & Yes & & & \\
\hline $\mathrm{R}^{2}$ & 0.870 & 0.849 & 0.852 & 0.783 & 0.811 & 0.812 & & & \\
\hline $\mathrm{N}$ & $3,609,572$ & $1,857,376$ & $1,160,458$ & 64,052 & 39,363 & 39,104 & & & \\
\hline \multicolumn{10}{|c|}{ Panel D: School-level avg. transition grade - 2005-2007 cohorts - between school cutoffs } \\
\hline $1\{$ Trans. grade $\geq$ Cutoff $\}$ & $\begin{array}{l}0.107^{*} \\
(0.001)\end{array}$ & $\begin{array}{r}0.107 \\
(0.001)\end{array}$ & $\begin{array}{r}0.106 \\
(0.001)\end{array}$ & $\begin{array}{r}0.435 \\
(0.006)\end{array}$ & $\begin{array}{l}0.414^{* * *} \\
(0.007)\end{array}$ & $\begin{array}{c}0.438 \\
(0.009)\end{array}$ & $\begin{array}{r}0.516 \\
(0.014)\end{array}$ & $\begin{array}{l}0.477 \\
(0.018)\end{array}$ & $\begin{array}{l}{ }^{*} 0.477 \\
(0.018)\end{array}$ \\
\hline Linear spline & Yes & Yes & Yes & Yes & Yes & Yes & Yes & Yes & Yes \\
\hline $\mathrm{R}^{2}$ & 0.830 & 0.808 & 0.811 & 0.669 & 0.700 & 0.691 & 0.700 & 0.700 & 0.700 \\
\hline $\mathrm{N}$ & $3,302,846$ & $1,611,388$ & $1,822,434$ & 62,503 & 34,855 & 22,485 & 11,838 & 6,559 & 6,382 \\
\hline
\end{tabular}

Note: All regressions are clustered at the student level and include cutoff fixed effects. All panels present reduced form specifications where the key independent variable is a dummy for whether a student's transition score is greater than or equal to the cutoff (normalized to zero). 
Table 4: Effects on Baccalaureate taking and performance

\begin{tabular}{|c|c|c|c|c|c|c|}
\hline \multirow[t]{2}{*}{ Dependent variable: } & \multicolumn{3}{|c|}{ All towns } & \multicolumn{3}{|c|}{ Survey towns } \\
\hline & $\begin{array}{c}\begin{array}{c}\text { Full } \\
\text { sample }\end{array} \\
(1) \\
\end{array}$ & $\begin{array}{c}\text { Within } \\
1 \text { point } \\
\text { of cutoff } \\
(2)\end{array}$ & $\begin{array}{l}\text { Within } \\
\text { IK } \\
\text { bound } \\
(3)\end{array}$ & $\begin{array}{c}\begin{array}{c}\text { Full } \\
\text { sample }\end{array} \\
(4) \\
\end{array}$ & $\begin{array}{c}\text { Within } \\
1 \text { point } \\
\text { of cutoff } \\
(5)\end{array}$ & $\begin{array}{c}\text { Within } \\
\text { IK } \\
\text { bound } \\
(6)\end{array}$ \\
\hline \multicolumn{7}{|c|}{$\overline{\text { Panel A: Bacc. taken dummy - 2001-2003 cohorts - between school cutoffs }}$} \\
\hline $1\{$ Trans. grade $\geq$ Cutoff $\}$ & $\begin{array}{r}0.001 \\
(0.001)\end{array}$ & $\begin{array}{r}0.000 \\
(0.001)\end{array}$ & $\begin{array}{r}0.001 \\
(0.001)\end{array}$ & $\begin{array}{c}0.0211^{* * * *} \\
(0.007)\end{array}$ & $\begin{array}{r}0.012 \\
(0.009)\end{array}$ & $\begin{array}{r}0.012 \\
(0.009)\end{array}$ \\
\hline Linear spline & Yes & Yes & Yes & Yes & Yes & Yes \\
\hline $\mathrm{R}^{2}$ & 0.056 & 0.054 & 0.059 & 0.086 & 0.081 & 0.080 \\
\hline $\mathrm{N}$ & $3,609,572$ & $1,857,376$ & $1,160,458$ & 64,052 & 39,363 & 39,104 \\
\hline \multicolumn{7}{|c|}{$\overline{\text { Panel B: Bacc. grade - 2001-2003 cohorts - between school cutoffs }}$} \\
\hline $1\{$ Trans. grade $\geq$ Cutoff $\}$ & $\begin{array}{r}0.037 \\
(0.001)\end{array}$ & $\begin{array}{c}0.018^{* * *} \\
(0.002)\end{array}$ & $\begin{array}{c}0.015^{* * *} \\
(0.003)\end{array}$ & $\begin{array}{l}0.144^{* * *} \\
(0.012)\end{array}$ & $\begin{array}{l}0.105^{* * *} \\
(0.015)\end{array}$ & $\begin{array}{c}0.104^{* * *} \\
(0.015)\end{array}$ \\
\hline Linear spline & Yes & Yes & Yes & Yes & Yes & Yes \\
\hline $\mathrm{R}^{2}$ & 0.567 & 0.483 & 0.472 & 0.566 & 0.494 & 0.494 \\
\hline $\mathrm{N}$ & $2,546,208$ & $1,256,038$ & 840,750 & 44,115 & 25,393 & 25,201 \\
\hline \multicolumn{7}{|c|}{ Panel C: Bacc. taken dummy - 2001-2003 cohorts - between track cutoffs } \\
\hline $1\{$ Trans. grade $\geq$ Cutoff $\}$ & $\begin{array}{c}-0.005 \\
(0.001)\end{array}$ & $\begin{array}{r}-0.001 \\
(0.001)\end{array}$ & $\begin{array}{r}-0.001 \\
(0.001)\end{array}$ & $\begin{array}{r}0.007 \\
(0.004)\end{array}$ & $\begin{array}{r}0.000 \\
(0.004)\end{array}$ & $\begin{array}{r}0.000 \\
(0.004)\end{array}$ \\
\hline Linear spline & Yes & Yes & Yes & Yes & Yes & Yes \\
\hline $\mathrm{R}^{2}$ & 0.060 & 0.057 & 0.059 & 0.091 & 0.084 & 0.086 \\
\hline $\mathrm{N}$ & $8,802,699$ & $4,845,812$ & $4,400,772$ & 265,896 & 172,656 & 154,366 \\
\hline \multicolumn{7}{|c|}{ Panel D: Bacc. grade - 2001-2003 cohorts - between track cutoffs } \\
\hline $1\{$ Trans. grade $\geq$ Cutoff $\}$ & $\begin{array}{r}0.042 \\
(0.001)\end{array}$ & $\begin{array}{l}0.011^{* * *} \\
(0.001)\end{array}$ & $\begin{array}{l}0.015^{* * *} \\
(0.001)\end{array}$ & $\begin{array}{l}0.062^{* * *} \\
(0.006)\end{array}$ & $\begin{array}{l}0.036^{* * *} \\
(0.007)\end{array}$ & $\begin{array}{l}0.037^{\text {*** }} \\
(0.007)\end{array}$ \\
\hline Linear spline & Yes & Yes & Yes & Yes & Yes & Yes \\
\hline $\mathrm{R}^{2}$ & 0.567 & 0.490 & 0.506 & 0.559 & 0.495 & 0.498 \\
\hline $\mathrm{N}$ & $6,165,081$ & $3,371,726$ & $3,923,073$ & 183,321 & 117,179 & 122,320 \\
\hline
\end{tabular}

Note: All regressions are clustered at the student level and include cutoff fixed effects. All panels present reduced form specifications where the key independent variable is a dummy for whether a student's transition score is greater than or equal to the cutoff (normalized to zero). 
Table 5: Heterogeneity in Baccalaureate effects (all specifications within 1 point of cutoffs)

\begin{tabular}{|c|c|c|c|c|c|c|}
\hline & $\begin{array}{c}\text { School } \\
\text { level } \\
\text { average } \\
\text { transition } \\
\text { score } \\
\text { (1) }\end{array}$ & $r$ & $\begin{array}{l}\text { Track- } \\
\text { level } \\
\text { average } \\
\text { transition } \\
\text { score } \\
(2)\end{array}$ & $r$ & $\begin{array}{c}\text { Baccalaureate } \\
\text { taken }\end{array}$ & $\begin{array}{l}\text { Baccalaureate } \\
\text { grade }\end{array}$ \\
\hline \multirow{2}{*}{$\begin{array}{l}\text { Panel A: Full sample } \\
1\{\text { Grade } \geq \text { Cutoff }\}\end{array}$} & & & & & & \\
\hline & $\begin{array}{r}0.107 \\
(0.001)\end{array}$ & & $\begin{array}{r}0.073 \\
(0.001)\end{array}$ & & $\begin{array}{r}0.000 \\
(0.001)\end{array}$ & $\begin{array}{l}0.018^{* * *} \\
(0.002)\end{array}$ \\
\hline Linear spline & Yes & & Yes & & Yes & Yes \\
\hline $\mathrm{R}^{2}$ & 0.790 & & 0.849 & & 0.054 & 0.483 \\
\hline $\mathrm{N}$ & $1,857,376$ & & $1,857,376$ & & $1,857,376$ & $1,256,038$ \\
\hline \multicolumn{7}{|l|}{ Panel B: Top tercile } \\
\hline $1\{$ Grade $\geq$ Cutoff $\}$ & $\begin{array}{r}0.158 \\
(0.002)\end{array}$ & & $\begin{array}{r}0.098 \\
(0.001)\end{array}$ & & $\begin{array}{r}0.003 \\
(0.002)\end{array}$ & $\begin{array}{l}0.048^{* * *} \\
(0.003)\end{array}$ \\
\hline Linear spline & Yes & & Yes & & Yes & Yes \\
\hline $\mathrm{R}^{2}$ & 0.749 & & 0.816 & & 0.028 & 0.448 \\
\hline $\mathrm{N}$ & 756,141 & & 756,141 & & 756,141 & 579,566 \\
\hline $\begin{array}{l}\text { Panel C: Bottom tercil } \\
1\{\text { Grade } \geq \text { Cutoff }\}\end{array}$ & $\begin{array}{r}0.099 \\
(0.003)\end{array}$ & & $\begin{array}{r}0.086 \\
(0.003)\end{array}$ & & $\begin{array}{r}-0.006 \\
(0.004)\end{array}$ & $\begin{array}{r}0.011 \\
(0.009)\end{array}$ \\
\hline Linear spline & Yes & & Yes & & Yes & Yes \\
\hline $\mathrm{R}^{2}$ & 0.459 & & 0.549 & & 0.050 & 0.222 \\
\hline $\mathrm{N}$ & 392,475 & & 392,475 & & 392,475 & 212,282 \\
\hline
\end{tabular}

Note: All regressions are clustered at the student level and include cutoff fixed effects. All panels present reduced form specifications where the key independent variable is a dummy for whether a student's transition score is greater than or equal to the cutoff (normalized to zero). For comparison, panel A replicates the I-K bound specifications in tables 3 and 4. Panels B and C present analogous specifications for the top and bottom tercile of cutoffs, respectively. 
Table 6: Teachers

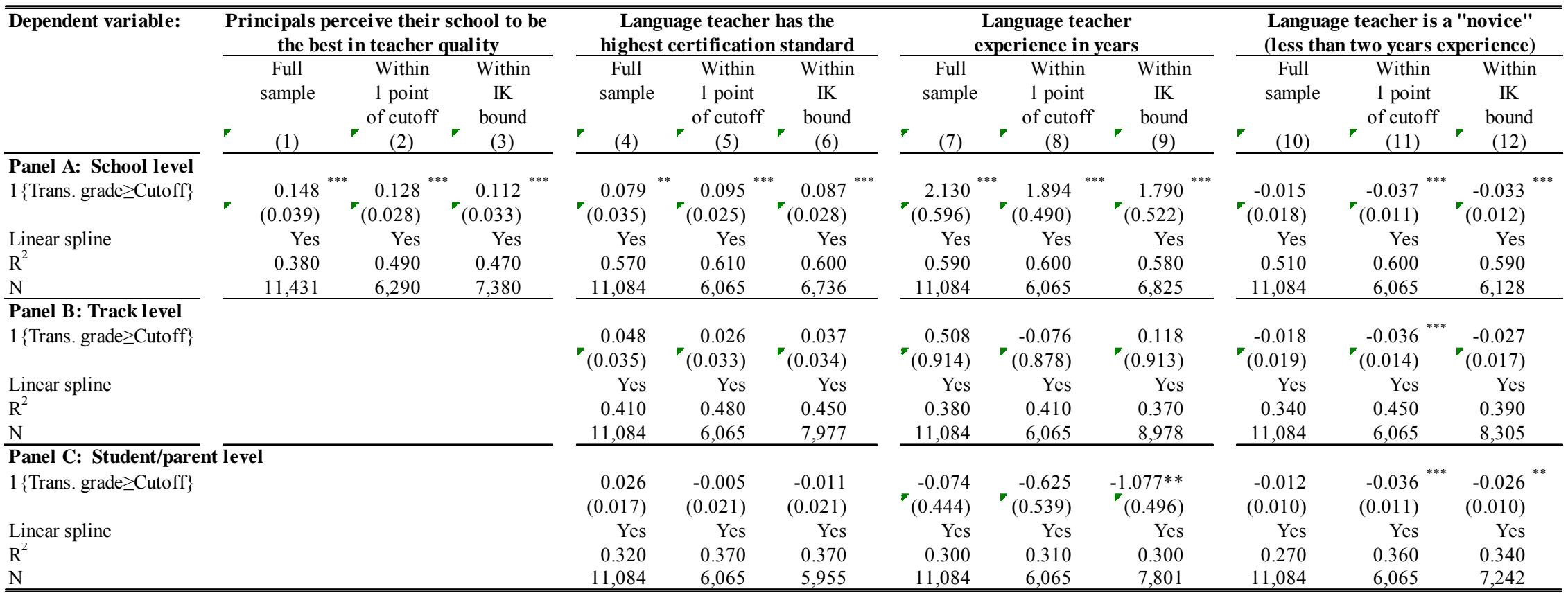

Note: All regressions include cutoff fixed effects. The regressions in Panel A are clustered at the school-cohort level, the regressions in Panel B are clustered at the school-track-cohort level, and the regressions in Panel C are clustered at the student level. All panels present reduced form specifications where the key independent variable is a dummy for whether a student's transition score is greater than or equal to the cutoff (normalized to zero). Panel A presents outcome variables that are aggregated at the school level. Panel B presents outcome variables that are aggregated at the track level. Panel C presents outcome variables that are at the child or parent level (see Section 6.4 for further discussion). 
Table 7: Parents

\begin{tabular}{|c|c|c|c|c|c|c|c|c|c|c|c|c|}
\hline \multirow[t]{2}{*}{ Dependent variable: } & \multicolumn{3}{|c|}{$\begin{array}{l}\text { Principals perceive their school to be } \\
\text { the best in parental participation }\end{array}$} & \multicolumn{3}{|c|}{$\begin{array}{c}\begin{array}{c}\text { Parents have volunteered } \\
\text { in the past year }\end{array} \\
\end{array}$} & \multicolumn{3}{|c|}{$\begin{array}{c}\text { Parents have paid for tutoring } \\
\text { services for child }\end{array}$} & \multicolumn{3}{|c|}{$\begin{array}{c}\text { Parents help child } \\
\text { with homework often }\end{array}$} \\
\hline & $\begin{array}{c}\text { Full } \\
\text { sample } \\
(1) \\
\end{array}$ & $\begin{array}{c}\text { Within } \\
1 \text { point } \\
\text { of cutoff } \\
(2)\end{array}$ & $\begin{array}{c}\text { Within } \\
\text { IK } \\
\text { bound } \\
(3)\end{array}$ & $\begin{array}{c}\begin{array}{c}\text { Full } \\
\text { sample }\end{array} \\
(4) \\
\end{array}$ & $\begin{array}{c}\text { Within } \\
1 \text { point } \\
\text { of cutoff } \\
(5)\end{array}$ & $\begin{array}{c}\text { Within } \\
\text { IK } \\
\text { bound } \\
(6) \\
\end{array}$ & $\begin{array}{c}\text { Full } \\
\text { sample } \\
(7) \\
\end{array}$ & $\begin{array}{c}\text { Within } \\
1 \text { point } \\
\text { of cutoff } \\
(8)\end{array}$ & $\begin{array}{c}\text { Within } \\
\text { IK } \\
\text { bound } \\
(9) \\
\end{array}$ & $\begin{array}{c}\text { Full } \\
\text { sample } \\
\\
(10) \\
\end{array}$ & $\begin{array}{c}\text { Within } \\
1 \text { point } \\
\text { of cutoff } \\
(11)\end{array}$ & $\begin{array}{c}\text { Within } \\
\text { IK } \\
\text { bound } \\
(12) \\
\end{array}$ \\
\hline $\begin{array}{l}\text { Panel A: School level } \\
1\{\text { Trans. grade } \geq \text { Cutoff }\}\end{array}$ & $\begin{array}{r}0.129 \\
(0.055)\end{array}$ & (0.044) & ${ }^{*} 0.130^{* * *}$ & $={ }^{0.011}{ }^{*}$ & ${ }^{0.012}{ }^{* *}$ & $(0.005)$ & ${ }\left(0.064^{* * *}\right.$ & ${ }^{0.0633^{* * *}}$ & $(0.010)$ & $\begin{array}{r}-0.003 \\
(0.009)\end{array}$ & $\begin{array}{r}0.000 \\
(0.007)\end{array}$ & $\begin{array}{r}0.000 \\
(0.007)\end{array}$ \\
\hline Linear spline & Yes & Yes & Yes & Yes & Yes & Yes & Yes & Yes & Yes & Yes & Yes & Yes \\
\hline $\mathrm{R}^{2}$ & 0.460 & 0.480 & 0.490 & 0.730 & 0.710 & 0.700 & 0.770 & 0.750 & 0.750 & 0.720 & 0.740 & 0.730 \\
\hline $\mathrm{N}$ & 11,047 & 6,139 & 5,558 & 11,776 & 6,522 & 7,142 & 11,757 & 6,501 & 7,255 & 11,723 & 6,488 & 9,674 \\
\hline $\begin{array}{l}\text { Panel B: Track level } \\
1\{\text { Trans. grade } \geq \text { Cutoff }\}\end{array}$ & & & & $\begin{array}{r}0.009 \\
(0.008)\end{array}$ & $\begin{array}{r}0.005 \\
(0.006)\end{array}$ & $\begin{array}{r}0.006 \\
(0.007)\end{array}$ & ${ }_{(0.012)}^{0.022}{ }^{*}$ & $\begin{array}{r}0.009 \\
(0.012)\end{array}$ & $\begin{array}{c}0.020^{*} \\
(0.011)\end{array}$ & $\begin{array}{r}-0.015 \\
(0.011)\end{array}$ & $={ }^{-0.026} 6^{* *}$ & $=(0.010)$ \\
\hline $\begin{array}{l}\text { Linear spline } \\
\mathrm{R}^{2} \\
\mathrm{~N}\end{array}$ & & & & $\begin{array}{r}\text { Yes } \\
0.470 \\
11,776 \\
\end{array}$ & $\begin{array}{r}\text { Yes } \\
0.490 \\
6,522 \\
\end{array}$ & $\begin{array}{r}\text { Yes } \\
0.470 \\
7,606 \\
\end{array}$ & $\begin{array}{r}\text { Yes } \\
0.590 \\
11,757 \\
\end{array}$ & $\begin{array}{r}\text { Yes } \\
0.550 \\
6,501 \\
\end{array}$ & $\begin{array}{r}\text { Yes } \\
0.560 \\
5,363 \\
\end{array}$ & $\begin{array}{r}\text { Yes } \\
0.480 \\
11,723 \\
\end{array}$ & $\begin{array}{r}\text { Yes } \\
0.500 \\
6,488 \\
\end{array}$ & $\begin{array}{r}\text { Yes } \\
0.500 \\
7,141 \\
\end{array}$ \\
\hline Panel C: Student/pal & evel & & & & & & & & & & & \\
\hline $1\{$ Trans. grade $\geq$ Cutoff $\}$ & & & & $\begin{array}{r}-0.001 \\
(0.011) \\
\text { Yes }\end{array}$ & $\begin{array}{r}-0.002 \\
(0.015) \\
\text { Yes }\end{array}$ & $\begin{array}{r}0.007 \\
(0.014) \\
\text { Yes }\end{array}$ & $\begin{array}{r}-0.009 \\
(0.014) \\
\text { Yes }\end{array}$ & $\begin{array}{r}-0.003 \\
(0.018) \\
\text { Yes }\end{array}$ & $\begin{array}{r}-0.003 \\
(0.017) \\
\text { Yes }\end{array}$ & $\begin{array}{r}-0.021 \\
(0.015) \\
\text { Yes }\end{array}$ & $\begin{array}{c}-0.043^{* *} \\
(0.019) \\
\text { Yes }\end{array}$ & $\begin{array}{c}-0.033 \\
(0.017) \\
\text { Yes }\end{array}$ \\
\hline $\mathrm{R}^{2}$ & & & & 0.070 & 0.070 & 0.070 & 0.170 & 0.130 & 0.130 & 0.080 & 0.090 & 0.090 \\
\hline $\mathrm{N}$ & & & & 11,776 & 6,522 & 7,905 & 11,757 & 6,501 & 6,771 & 11,723 & 6,488 & 8,840 \\
\hline
\end{tabular}

Note: All All regressions include cutoff fixed effects. The regressions in Panel A are clustered at the school-cohort level, the regressions in Panel B are clustered at the school-track-cohort level, and the regressions in Panel C are clustered at the student level. All panels present reduced form specifications where the key independent variable is a dummy for whether a student's transition score is greater than or equal to the cutoff (normalized to zero). Panel A presents outcome variables that are aggregated at the school level. Panel B presents outcome variables that are aggegated at the track level. Panel C presents outcome variables that are at the child or parent level (see Section 6.4 for further discussion). 
Table 8: Peers

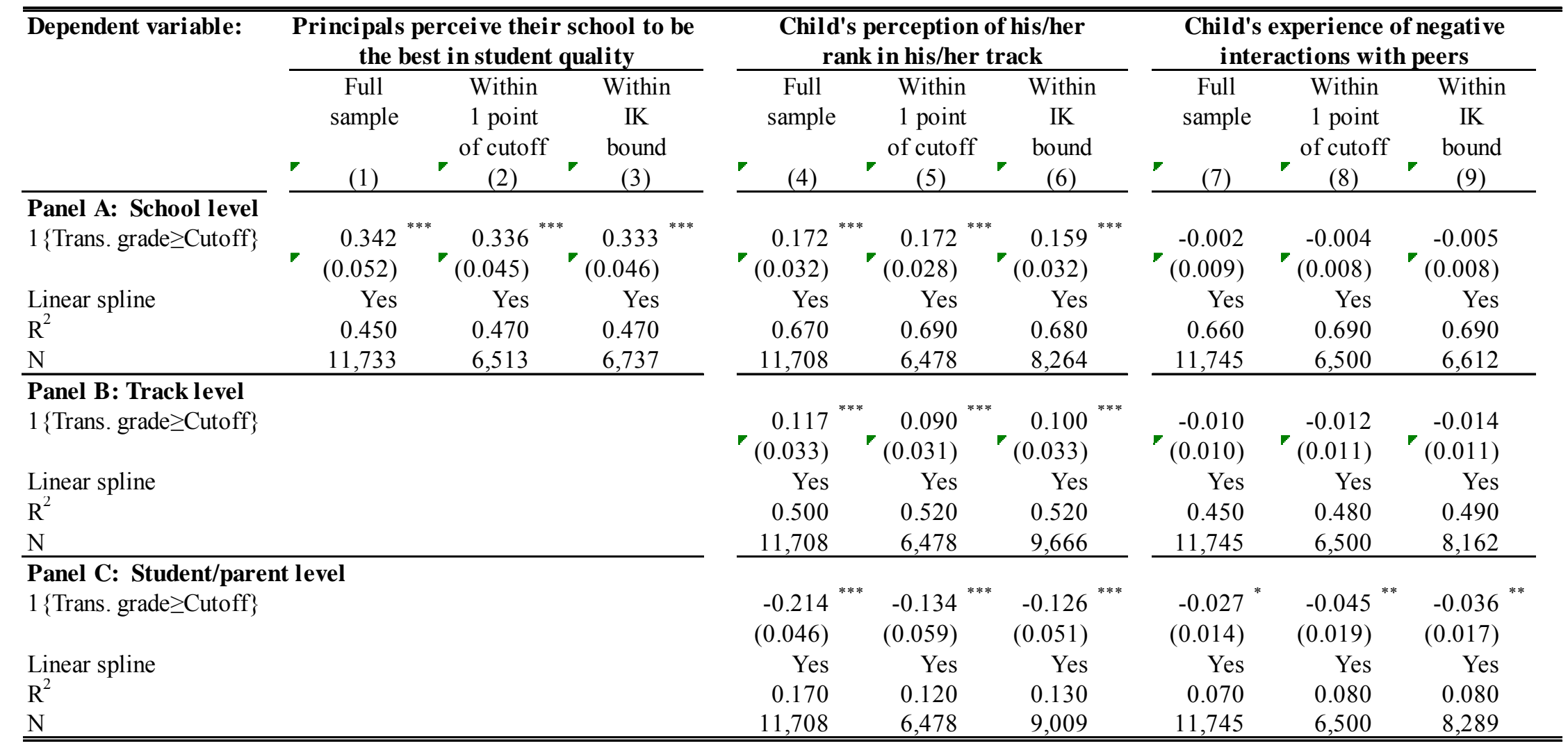

Note: All regressions include cutoff fixed effects. The regressions in Panel A are clustered at the school-cohort level, the regressions in Panel B are clustered at the school-track-cohort level, and the regressions in Panel C are clustered at the student level. All panels present reduced form specifications where the key independent variable is a dummy for whether a student's transition score is greater than or equal to the cutoff (normalized to zero). Panel A presents outcome variables that are aggregated at the school level. Panel B presents outcome variables that are aggegated at the track level. Panel C presents outcome variables that are at the child or parent level (see Section 6.4 for further discussion). 
Table 9: Child homework

\begin{tabular}{|c|c|c|c|c|c|c|c|c|c|}
\hline \multirow[t]{2}{*}{ Dependent variable: } & \multicolumn{3}{|c|}{$\begin{array}{l}\text { Child does homework every day } \\
\text { or almost every day (child report) }\end{array}$} & \multicolumn{3}{|c|}{$\begin{array}{l}\text { Child does homework every day } \\
\text { or almost every day (parent report) }\end{array}$} & \multicolumn{3}{|c|}{$\begin{array}{l}\text { Index: Child perceives } \\
\text { homework to be easy }\end{array}$} \\
\hline & $\begin{array}{c}\begin{array}{c}\text { Full } \\
\text { sample }\end{array} \\
(1) \\
\end{array}$ & $\begin{array}{c}\text { Within } \\
1 \text { point } \\
\text { of cutoff } \\
(2)\end{array}$ & $\begin{array}{c}\text { Within } \\
\text { IK } \\
\text { bound } \\
(3) \\
\end{array}$ & $\begin{array}{c}\begin{array}{c}\text { Full } \\
\text { sample }\end{array} \\
(4) \\
\end{array}$ & $\begin{array}{c}\text { Within } \\
1 \text { point } \\
\text { of cutoff } \\
(5)\end{array}$ & $\begin{array}{c}\text { Within } \\
\text { IK } \\
\text { bound } \\
(6)\end{array}$ & $\begin{array}{c}\text { Full } \\
\text { sample } \\
(7) \\
\end{array}$ & $\begin{array}{c}\text { Within } \\
1 \text { point } \\
\text { of cutoff } \\
(8)\end{array}$ & $\begin{array}{c}\text { Within } \\
\text { IK } \\
\text { bound } \\
(9) \\
\end{array}$ \\
\hline $\begin{array}{l}\text { Panel A: School level } \\
1\{\text { Trans. grade } \geq \text { Cutoff }\}\end{array}$ & $\begin{array}{r}0.078 \\
(0.014)\end{array}$ & ${ }^{*} \quad 0.072^{* * *}$ & ${ }^{*} 0.068^{* * *}$ & $(0.013)$ & $(0.012)$ & $\begin{array}{l}0.092^{* * *} \\
(0.012)\end{array}$ & $(0.028)$ & $\begin{array}{r}0.038 \\
(0.024)\end{array}$ & $\begin{array}{r}0.027 \\
(0.026)\end{array}$ \\
\hline $\begin{array}{l}\text { Linear spline } \\
\mathrm{R}^{2} \\
\mathrm{~N}\end{array}$ & $\begin{array}{r}\text { Yes } \\
0.730 \\
11,815\end{array}$ & $\begin{array}{r}\text { Yes } \\
0.770 \\
6,544\end{array}$ & $\begin{array}{r}\text { Yes } \\
0.750 \\
8,262\end{array}$ & $\begin{array}{r}\text { Yes } \\
0.750 \\
11,689\end{array}$ & $\begin{array}{r}\text { Yes } \\
0.760 \\
6,471\end{array}$ & $\begin{array}{r}\text { Yes } \\
0.760 \\
6,584\end{array}$ & $\begin{array}{r}\text { Yes } \\
0.730 \\
9,556\end{array}$ & $\begin{array}{r}\text { Yes } \\
0.760 \\
5,468\end{array}$ & $\begin{array}{r}\text { Yes } \\
0.750 \\
6,557\end{array}$ \\
\hline $\begin{array}{l}\text { Panel B: Track level } \\
1\{\text { Trans. grade } \geq \text { Cutoff }\}\end{array}$ & $\begin{array}{r}0.067 \\
(0.014)\end{array}$ & $\begin{array}{l}{ }^{*} \\
\left(0.0500^{* * *}\right.\end{array}$ & ${ }^{*} \quad 0.056^{* * *}$ & $(0.014)$ & $(0.013)$ & $\begin{array}{l}0.075^{* * *} \\
(0.014)\end{array}$ & $\begin{array}{r}0.045 \\
(0.032)\end{array}$ & $\begin{array}{r}0.011 \\
(0.031)\end{array}$ & $\begin{array}{r}0.011 \\
(0.031)\end{array}$ \\
\hline $\begin{array}{l}\text { Linear spline } \\
\mathrm{R}^{2} \\
\mathrm{~N}\end{array}$ & $\begin{array}{r}\text { Yes } \\
0.570 \\
11,815\end{array}$ & $\begin{array}{r}\text { Yes } \\
0.610 \\
6,544\end{array}$ & $\begin{array}{r}\text { Yes } \\
0.600 \\
8,565\end{array}$ & $\begin{array}{r}\text { Yes } \\
0.600 \\
11,689\end{array}$ & $\begin{array}{r}\text { Yes } \\
0.640 \\
6,471\end{array}$ & $\begin{array}{r}\text { Yes } \\
0.630 \\
6,793\end{array}$ & $\begin{array}{r}\text { Yes } \\
0.510 \\
9,556\end{array}$ & $\begin{array}{r}\text { Yes } \\
0.560 \\
5,468\end{array}$ & $\begin{array}{r}\text { Yes } \\
0.550 \\
6,478\end{array}$ \\
\hline Panel C: Stu & evel & & & & & & & & \\
\hline $1\{$ Trans. grade $\geq$ Cutoff $\}$ & $\begin{array}{r}0.020 \\
(0.018)\end{array}$ & $\begin{array}{r}0.024 \\
(0.023)\end{array}$ & $\begin{array}{r}0.019 \\
(0.019)\end{array}$ & $\begin{array}{l}0.081^{* * *} \\
(0.017)\end{array}$ & $\begin{array}{l}0.051^{* *} \\
(0.021)\end{array}$ & $\begin{array}{l}0.046^{* *} \\
(0.020)\end{array}$ & $\begin{array}{r}-0.023 \\
(0.042)\end{array}$ & $\begin{array}{r}-0.021 \\
(0.053)\end{array}$ & $\begin{array}{r}-0.020 \\
(0.047)\end{array}$ \\
\hline Linear spline & Yes & Yes & Yes & Yes & Yes & Yes & Yes & Yes & Yes \\
\hline $\mathrm{R}^{2}$ & 0.160 & 0.180 & 0.170 & 0.170 & 0.200 & 0.190 & 0.120 & 0.140 & 0.130 \\
\hline $\mathrm{N}$ & 11,815 & 6,544 & 9,999 & 11,689 & 6,471 & 7,177 & 9,556 & 5,468 & 7,042 \\
\hline
\end{tabular}

Note: All All regressions include cutoff fixed effects. The regressions in Panel A are clustered at the school-cohort level, the regressions in Panel B are clustered at the school-track-cohort level, and the regressions in Panel C are clustered at the student level. All panels present reduced form specifications where the key independent variable is a dummy for whether a student's transition score is greater than or equal to the cutoff (normalized to zero). Panel A presents outcome variables that are aggregated at the school level. Panel B presents outcome variables that are aggegated at the track level. Panel C presents outcome variables that are at the child or parent level (see Section 6.4 for further discussion). 
Table 10: Class effects (all specifications within 1 point of cutoffs)

\begin{tabular}{|c|c|c|c|c|c|c|c|c|c|c|c|c|}
\hline \multirow[t]{2}{*}{ Dependent variable: } & \multirow[b]{2}{*}{$\begin{array}{c}\text { First Stage } \\
\text { Class } \\
\text { level } \\
\text { transition } \\
\text { score } \\
\\
\\
\end{array}$} & \multicolumn{3}{|c|}{ Teachers } & \multicolumn{3}{|c|}{ Parents } & \multicolumn{2}{|c|}{ Peers } & \multicolumn{3}{|c|}{ Child } \\
\hline & & $\begin{array}{c}\text { Language } \\
\text { teacher } \\
\text { has the } \\
\text { highest } \\
\text { certification } \\
\text { (2) } \\
\end{array}$ & $\begin{array}{c}\text { Language } \\
\text { teacher } \\
\text { experience } \\
\text { (in years) } \\
\\
\\
\end{array}$ & $\begin{array}{c}\text { Language } \\
\text { teacher has } \\
\text { two or less } \\
\text { years } \\
\text { experience } \\
(4) \\
\end{array}$ & $\begin{array}{c}\text { Parents } \\
\text { have } \\
\text { volunteered } \\
\text { in the } \\
\text { past year } \\
\text { (5) }\end{array}$ & $\begin{array}{l}\text { Parents } \\
\text { have } \\
\text { paid for } \\
\text { tutoring } \\
\text { services } \\
(6)\end{array}$ & 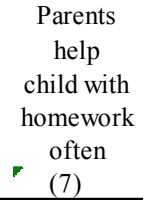 & $\begin{array}{l}\text { Child's } \\
\text { perception } \\
\text { of his/her } \\
\text { rank in } \\
\text { track } \\
(8) \\
\end{array}$ & $\begin{array}{c}\text { Child's } \\
\text { negative } \\
\text { interaction } \\
\text { with peers } \\
\quad(9) \\
\end{array}$ & $\begin{array}{l}\text { Child does } \\
\text { homework } \\
\text { almost } \\
\text { every day } \\
\text { (child report) } \\
\text { (10) }\end{array}$ & $\begin{array}{c}\text { Child does } \\
\text { homework } \\
\text { almost } \\
\text { every day } \\
\text { (parent report) } \\
\text { (11) }\end{array}$ & $\begin{array}{c}\text { Child } \\
\text { perceives } \\
\text { homework } \\
\text { to be } \\
\text { easy } \\
(12) \\
\end{array}$ \\
\hline $\begin{array}{l}\text { Panel A: Class level } \\
1\{\text { Trans. grade } \geq \text { Cutoff }\}\end{array}$ & ${ }^{2}\left(0.127^{* * *}\right.$ & $\begin{array}{r}0.046 \\
\quad(0.021)\end{array}$ & ( $1.832^{* * *}$ & $\begin{array}{r}-0.006 \\
(0.006)\end{array}$ & $\begin{array}{r}0.006 \\
(0.005)\end{array}$ & $\begin{array}{c}0.0266^{* *} \\
(0.007)\end{array}$ & "r $\begin{array}{r}0.004 \\
(0.005)\end{array}$ & ${ }_{(0.019)}^{0.044}{ }^{* *}$ & $\begin{array}{r}-0.007 \\
(0.005)\end{array}$ & $\begin{array}{l}0.021^{* * *} \\
(0.008)\end{array}$ & ${ }^{*} \quad 0^{0.017^{* *}}$ & $\begin{array}{c}0.032 \\
(0.02)\end{array}$ \\
\hline Linear spline & Yes & Yes & Yes & Yes & Yes & Yes & Yes & Yes & Yes & Yes & Yes & Yes \\
\hline $\mathrm{R}^{2}$ & 0.890 & 0.560 & 0.600 & 0.530 & 0.560 & 0.740 & 0.590 & 0.620 & 0.520 & 0.720 & 0.700 & 0.620 \\
\hline $\mathrm{N}$ & 5,396 & 5,179 & 5,179 & 5,179 & 5,362 & 5,346 & 5,349 & 5,342 & 5,350 & 5,385 & 5,355 & 4,443 \\
\hline \multirow{2}{*}{\multicolumn{5}{|c|}{$\begin{array}{l}\text { Panel B: Student/parent level } \\
1\{\text { Trans. grade } \geq \text { Cutoff }\}\end{array}$}} & & & & & & & & \\
\hline & & & & & $\begin{array}{r}-0.008 \\
(0.012)\end{array}$ & $\begin{array}{r}-0.001 \\
(0.016)\end{array}$ & $\begin{array}{r}-0.012 \\
(0.015)\end{array}$ & ${ }^{-0.142^{* * *}}(0.047)$ & $\begin{array}{l}-0.018 \\
(0.013)\end{array}$ & $\begin{array}{r}0.003 \\
(0.017)\end{array}$ & $\begin{array}{r}0.010 \\
(0.015)\end{array}$ & $\begin{array}{l}-0.032 \\
(0.042)\end{array}$ \\
\hline Linear spline & & & & & Yes & Yes & Yes & Yes & Yes & Yes & Yes & Yes \\
\hline $\mathrm{R}^{2}$ & & & & & 0.120 & 0.250 & 0.120 & 0.200 & 0.100 & 0.240 & 0.230 & 0.190 \\
\hline $\mathrm{N}$ & & & & & 5,373 & 5,357 & 5,360 & 5,353 & 5,361 & 5,396 & 5,366 & 4,453 \\
\hline
\end{tabular}

Note: All regressions include cutoff fixed effects. The regressions in Panel A are clustered at the school-class-cohort level and the regressions in Panel B are clustered at the student level. All panels present reduced form specifications where the key independent variable is a dummy for whether a student's transition score is greater than or equal to the cutoff (normalized to zero). Panel A presents outcome variables that are aggregated at the class level. Panel B presents outcome variables that are at the child or parent level. 
Table 11: Marginal effects across cohorts

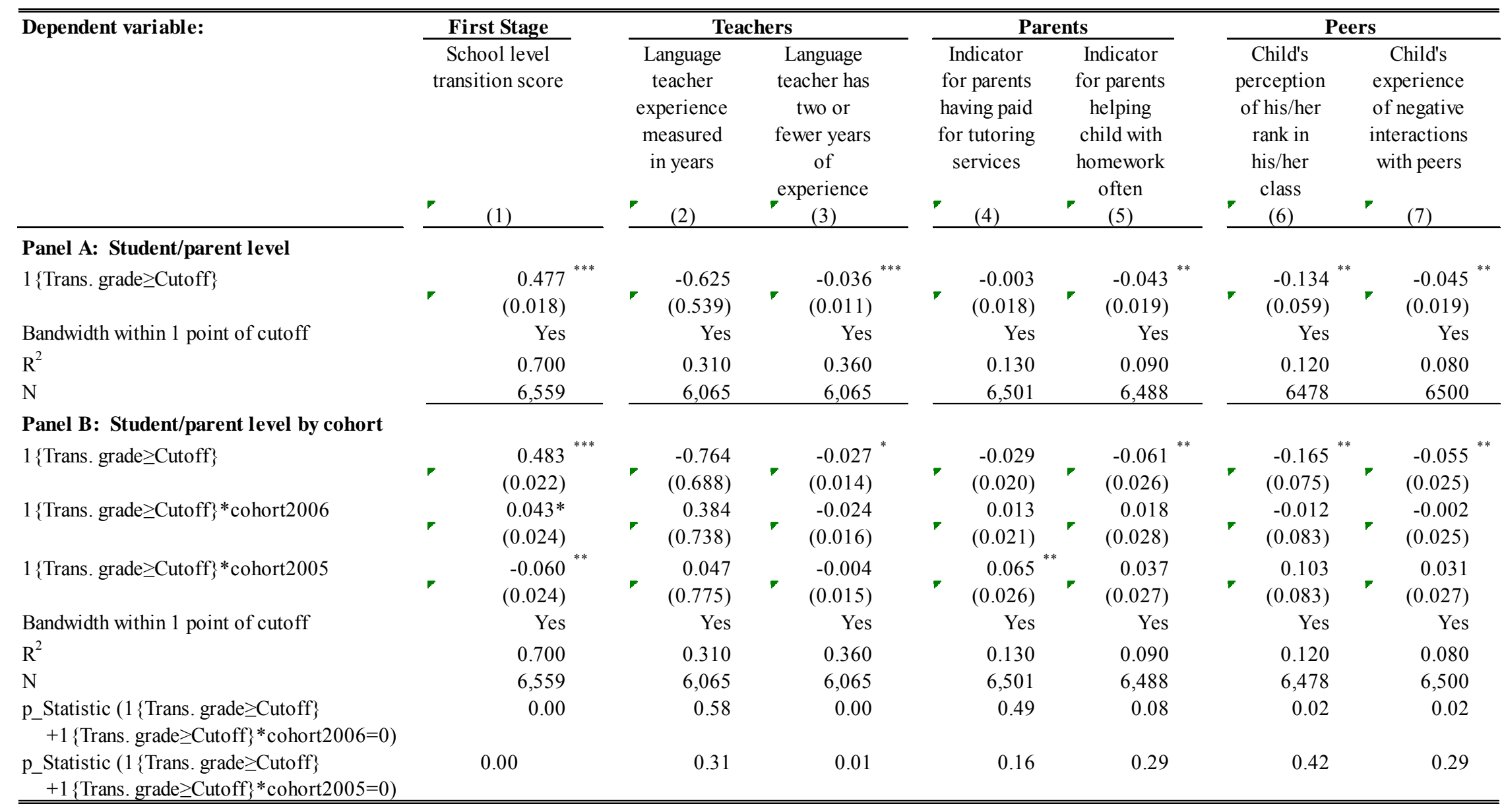

Note: All regressions are clustered at the student level and include cutoff fixed effects. All panels present reduced form specifications where the key independent variable is a dummy for whether a student's transition score is greater than or equal to the cutoff (normalized to zero). Panel A presents outcome variables that are aggegated at the child or parent level. Panel B presents outcome variables that are at the child or parent level and it also includes interactions of for being in the 2005 and 2006 entry cohort with the dummy for whether a student's transition score is greater than or equal to the cutoff. 
Table A.1: Continuity checks

\begin{tabular}{|c|c|c|c|c|c|c|c|c|c|}
\hline & \multicolumn{9}{|c|}{ Dependent variable } \\
\hline & $\begin{array}{c}\text { Mother's } \\
\text { birthyear } \\
\text { (1) }\end{array}$ & $\begin{array}{c}\text { Mother } \\
\text { is } \\
\text { Romanian } \\
\text { (2) }\end{array}$ & $\begin{array}{c}\text { Mother } \\
\text { is } \\
\text { Hungarian } \\
\text { (3) }\end{array}$ & $\begin{array}{l}\text { Mother } \\
\text { is } \\
\text { Roma } \\
\text { (4) }\end{array}$ & $\begin{array}{c}\text { Mother has } \\
\text { has } \\
\text { primary } \\
\text { education } \\
\text { (5) }\end{array}$ & $\begin{array}{l}\text { Mother has } \\
\text { has } \\
\text { secondary } \\
\text { education } \\
(6)\end{array}$ & $\begin{array}{c}\text { Mother has } \\
\text { has } \\
\text { tertiary } \\
\text { education } \\
(7)\end{array}$ & $\begin{array}{c}\text { Child Gender } \\
\text { gender }\end{array}$ & $\begin{array}{l}\text { Child's } \\
\text { birthyear }\end{array}$ \\
\hline Panel A: Full sample & $\begin{array}{l}-0.297 \\
{[0.240]}\end{array}$ & $\begin{array}{l}-0.001 \\
{[0.008]}\end{array}$ & $\begin{array}{c}0.001 \\
{[0.007]}\end{array}$ & $\begin{array}{l}-0.002 \\
{[0.003]}\end{array}$ & $\begin{array}{l}-0.002 \\
{[0.005]}\end{array}$ & $\begin{array}{l}0.039^{*} \\
{[0.020]}\end{array}$ & $\begin{array}{c}-0.022 * * \\
{[0.009]}\end{array}$ & $\begin{array}{c}0.026 \\
{[0.019]}\end{array}$ & $\begin{array}{c}0.013 \\
{[0.019]}\end{array}$ \\
\hline Panel B: Within 1 point of cutoff & $\begin{array}{l}-0.222 \\
{[0.317]}\end{array}$ & $\begin{array}{c}0.003 \\
{[0.011]}\end{array}$ & $\begin{array}{c}0.000 \\
{[0.009]}\end{array}$ & $\begin{array}{c}0.000 \\
{[0.004]}\end{array}$ & $\begin{array}{c}0.001 \\
{[0.006]}\end{array}$ & $\begin{array}{l}-0.003 \\
{[0.026]}\end{array}$ & $\begin{array}{l}-0.005 \\
{[0.011]}\end{array}$ & $\begin{array}{c}0.025 \\
{[0.024]}\end{array}$ & $\begin{array}{c}0.032 \\
{[0.025]}\end{array}$ \\
\hline Panel C: Within IK bounds & $\begin{array}{l}-0.325 \\
{[0.278]}\end{array}$ & $\begin{array}{c}0.003 \\
{[0.010]}\end{array}$ & $\begin{array}{c}0.003 \\
{[0.008]}\end{array}$ & $\begin{array}{l}-0.002 \\
{[0.004]}\end{array}$ & $\begin{array}{c}0.001 \\
{[0.006}\end{array}$ & $\begin{array}{c}0.018 \\
{[0.023]}\end{array}$ & $\begin{array}{l}-0.014 \\
{[0.009]}\end{array}$ & $\begin{array}{c}0.027 \\
{[0.021]}\end{array}$ & $\begin{array}{c}0.017 \\
{[0.023]}\end{array}$ \\
\hline
\end{tabular}

Note: All regressions are clustered at the student level and include cutoff fixed effects. All results are based on reduced form specifications where the key independent variable is a dummy for whether a student's transition score is greater than or equal to the cutoff (normalized to zero). All outcome variables are at the child or parent level (see Section 6.4 for further discussion). 
Figure A.1: Top and bottom cutoffs in towns with 3 or more schools; 2-school towns
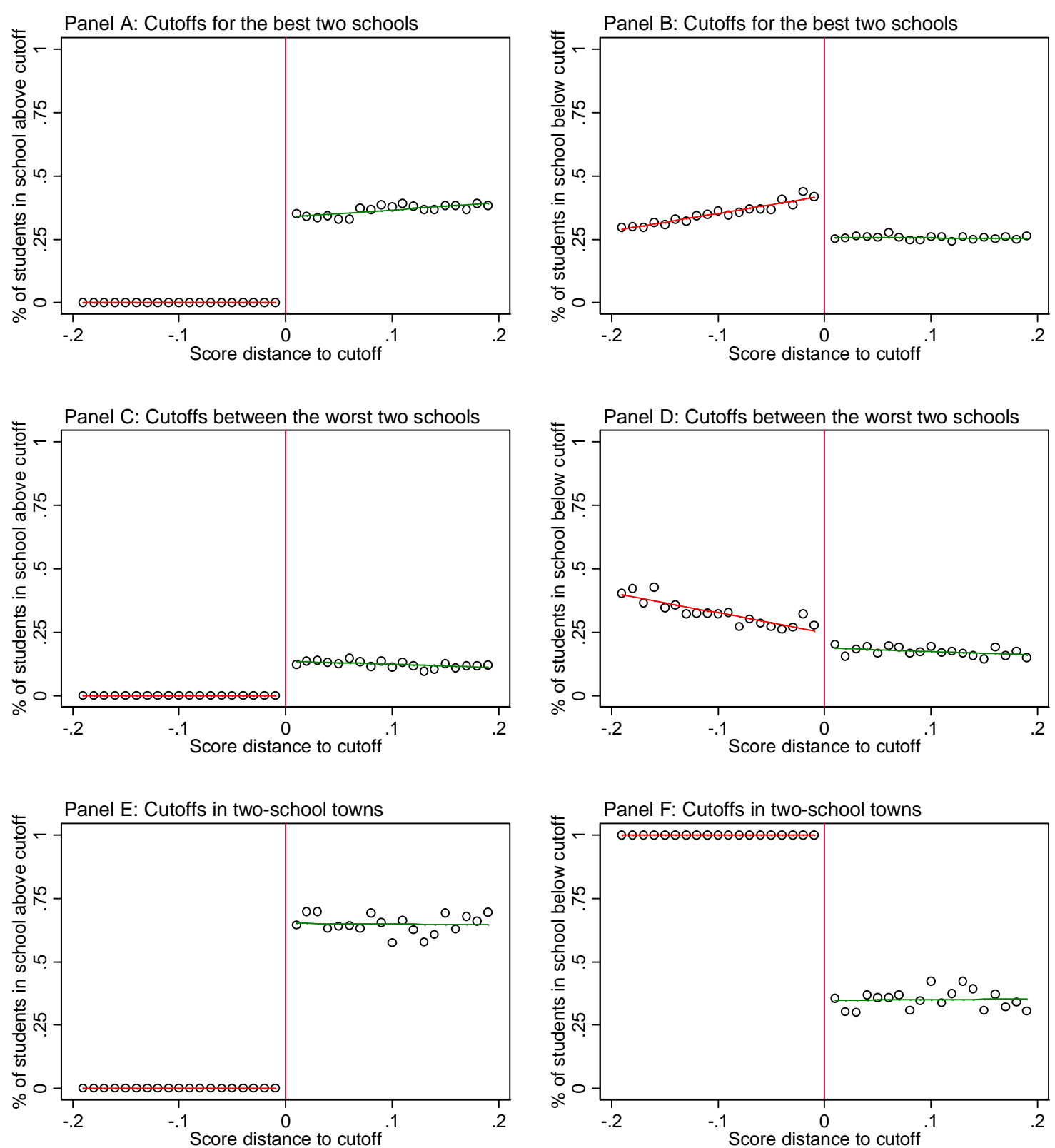

Note: Panels A and B describe cutoffs that determine access to the best school in towns that contain at least three schools. Panels C and D refer to the lowest cutoffs in such towns. Panels E and F describe the cutoffs in two-school towns. All panels are restricted to individuals with a transition score within 0.2 points of a cutoff. The left hand panels plot ( 0.01 point) transition cell means of the proportion of students who attend the school above the cutoff; the right hand side ones the proportion of students who enroll in the school below. The solid lines plot fitted values of residuals from regressions of the dependent variable on a linear trend in the transition score, estimated separately on each side of the cutoff. 